10 years ESJ

Special edition

\title{
Estrategias Mercadológicas para Enfrentar el Covid-19, Ixtapaluca, Nezahualcóyotl e Iztapalapa, México
}

\author{
Alejandra Ballesteros Aureoles \\ José Antonio Tlacuilo González \\ María de Lourdes Jiménez Calvo \\ Universidad Tecnológica de Nezahualcóyotl, México
}

Doi: $10.19044 /$ esj.2021.v17n4p182

Submitted: 28 October 2020

Accepted: 15 January 2021

Published: 07 February 2021
Copyright 2021 Author(s)

Under Creative Commons BY-NC-ND

4.0 OPEN ACCESS

Cite As:

Aureoles B.A., Tlacuilo González J.A. \& Jiménez Calvo M.L.(2021). Estrategias Mercadológicas para Enfrentar el Covid-19, Ixtapaluca, Nezahualcóyotl e Iztapalapa, México. European Scientific Journal, ESJ, 17(4), 182.

https://doi.org/10.19044/esj.2021.v17n4p182

\section{Resumen}

Las empresas y la sociedad en México y el mundo han tenido que enfrentar la Pandemia del Covid-19, adentrándolas en la búsqueda por las mejores estrategias; así como, en la investigación por conocer cuáles se han usado, planteándose como objetivos: 1. conocer las estrategias mercadológicas, específicamente del marketing directo y digital, que usan las empresas de los Municipios de Ixtapaluca, Nezahualcóyotl y la Alcaldía de Iztapalapa en México; 2 . conocer las Apps que los estudiantes usaban antes y durante la pandemia. Para cumplir con los objetivos planteados, el marco teórico se fundamenta en la revisión de los conceptos de Marketing directo y marketing digital conceptualizados por Kotler (2017), Fischer y Espejo (2017). El método de investigación utilizado está divido en dos partes, en el primero se aplica una investigación cuantitativa a través de un cuestionario de 37 preguntas aplicado a 78 estudiantes residentes del Municipio de Nezahualcóyotl, para conocer el uso de las Apps antes y durante la pandemia del Covid-19 y en la segunda parte se aplica el método descriptivo usando la observación y recolección de fotografías. Los resultados fueron presentados en la selección de algunas gráficas y con lista de las diferentes estrategias mercadológicas que usaron las empresas. Básicamente con el uso de las redes sociales como el Facebook y el WhatsApp, o herramientas como catálogos digitales y el asistente virtual. En la sección de la discusión y las conclusiones 
se sabe que la Pandemia no termina y es necesario continuar con el apoyo a empresas y la sociedad en general.

Palabras clave: Marketing Directo, Marketing Digital, Social Media, Apps, Pandemia del Covid-19

\title{
Marketing Strategies to Face Covid-19 in Ixtapaluca, Nezahualcóyotl and Iztapalapa, Mexico
}

\author{
Alejandra Ballesteros Aureoles \\ José Antonio Tlacuilo González. \\ María de Lourdes Jiménez Calvo \\ Universidad Tecnológica de Nezahualcóyotl, México
}

\begin{abstract}
Companies and society in Mexico and the world had to face the Covid19 pandemic. This has made them to carry out various investigation with the aim to: 1 . Know the marketing strategies, specifically direct and digital marketing, used by the companies of the Municipalities of Ixtapaluca, Nezahualcóyotl and the Mayor of Iztapalapa in Mexico; 2. Know the apps students used before and during the pandemic. To achieve the objectives set out, the theoretical framework was based on the revision of the concept of Direct Marketing and Digital Marketing conceptualized by Kotler (2017) and Fischer and Espejo (2017). The research method used is divided into two parts. The first part applies a quantitative research through a 37-item questionnaire distributed to 78 students residing in the Municipality of Nezahualcóyotl to understand the use of the apps before and during the Covid-19 pandemic. For the second part, the descriptive method is applied using observation and collection of photographs. The results were presented in the selection of some graphs and with a list of the different marketing strategies used by the companies. This includes the use of social networks like Facebook and WhatsApp, or tools like digital catalogs and virtual assistant. The discussion section and conclusions shows that the pandemic has not ended, and it is necessary to continue to support businesses and society at large using the different digital marketing channels.
\end{abstract}

Keywords: Direct Marketing, Digital Marketing, Social Media, Apps, Covid19 Pandemic 


\section{Introduction}

La mercadotecnia en las organizaciones se utiliza cada vez más para acercar a los consumidores actuales los productos de forma más eficiente, así como para satisfacer sus gustos, necesidades y deseos sin perjudicar, a su vez, a los consumidores futuros mediante una mercadotecnia responsable, esta, es la razón de ser de la teoría de la mercadotecnia (Fischer, 2020).

Las recomendaciones y una revisión a nivel macroeconómico, con toda la serie de políticas nacionales e internacionales han dado una lista de soluciones y propuestas para enfrentar la pandemia del Covid-19. Pero el objetivo de esta investigación es un trabajo a nivel microeconómico, donde se muestra lo que en realidad tuvieron que hacer las empresas cercanas, al entorno, en el día a día, con la cotidianidad de las empresas que nunca cerraron, que cerraron parcialmente o que tuvieron que cerrar definitivamente.

Se plantean dos objetivos de investigación, el primero es conocer las estrategias mercadológicas que las empresas de los municipios de Ixtapaluca y Nezahualcóyotl, municipios ubicados en el Estado de México y la alcaldía de Iztapalapa en la Ciudad de México, tuvieron que utilizar para enfrentar los estragos de vivir con la pandemia del Covid-19, desde el 19 de marzo y hasta el mes de septiembre de 2020, el segundo conocer el uso del comportamiento de las Apps antes y durante la Pandemia del Covid-19 entre un grupo de estudiantes.

La pregunta de investigación que se pretende responder es ¿Cuáles son las estrategias que las empresas han utilizado para enfrentar esta pandemia de la llamada Covid-19?

El método esta divido en dos partes, en el primero se aplica una investigación cuantitativa a través de un cuestionario de 37 preguntas a estudiantes residentes del Municipio de Nezahualcóyotl, para conocer el uso de las Apps antes y durante la pandemia del Covid-9 y en la segunda se aplica un método descriptivo usando la observación y recolección de fotografías como evidencia de las estrategias mercadológicas.

Se presentan en los hallazgos los principales resultados en el uso de redes sociales y Apps, al final la discusión, conclusiones y las referencias.

\section{Antecedentes COVID-19 por SARS-CoV-2, en el mundo}

En el informe del Gobierno Mexicano de fecha 27 de febrero de 2020, se presentan estos antecedentes. (Gobierno de México, 2020)

El 31 de diciembre de 2019, autoridades de salud de la ciudad de Wuhan, provincia de Hubei, China informaron sobre la presencia de un conglomerado de 27 casos de Síndrome Respiratorio Agudo de etiología desconocida, estableciendo un vínculo con un mercado de mariscos y animales. 
El 7 de enero de 2020, las autoridades chinas informaron la presencia de un Nuevo Coronavirus (2019-nCoV) identificado como posible etiología de dicho síndrome. El 13 de enero de 2020, el Ministerio de Salud Pública de Tailandia reportó el primer caso confirmado por laboratorio de 2019-nCoV en un paciente de 61 años residente de Wuhan, China. El 14 de enero, Japón informó la presencia de un caso de neumonía. El 20 de enero, Corea del Sur notificó un caso.

Llega al continente americano el 21 de enero EE. UU. El día 30 de enero, la OMS declaró Emergencia de Salud Pública de Importancia Internacional (ESPII), por el brote de 2019-nCoV. El 11 de febrero, la Organización Mundial de la Salud, en conjunto con la Organización Mundial de Sanidad Animal (OIE) y la Organización de las Naciones Unidas para la Agricultura y la Alimentación (FAO), anunció el nombre de la enfermedad como COVID-19, por sus siglas en inglés, "enfermedad por coronavirus 2019". El 26 de febrero, se confirma el primes caso en América Latina, por el cuándo el Ministerio de Salud de Brasil.

\section{Antecedentes COVID-19 por SARS-CoV-2, en México}

En el Informe epidemiológico de fecha 27 de febrero del 2020, se reporta la Situación epidemiológica, en el país no se habían presentado casos confirmados de enfermedad por COVID-19 (Gobierno de México, 2020).

El 28 de febrero de 2020, en México se confirmaron los tres primeros casos de COVID-19, dos en Guanajuato y uno en Durango. Para el 29 de febrero de 2020, ya había un reporte de casos en diferentes estados, las autoridades confirmaron 125 casos, siendo 11 en la Ciudad de México y 4 en el Estado de México. La distribución por género 52\% en hombres, con una edad media de 43 años. Ver Figura 1 y Tabla 1. En la Figura 2, se muestra el numero de casos confirmados de fecha 30 de septiembre de 2020. 
Figura 1. Estados donde se presentaron los primeros casos de Covid-19 en México de fecha 29 de febrero de 2020.

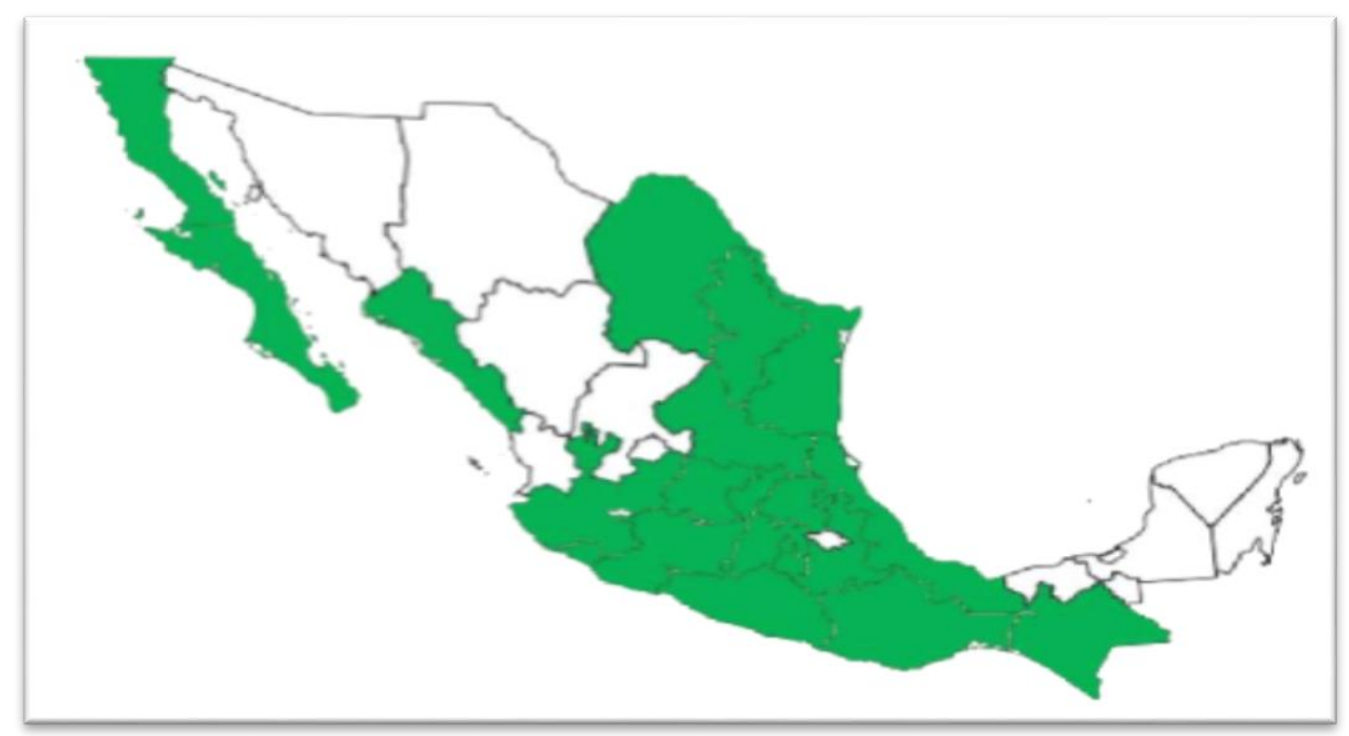

Fuente: Gobierno de México. (2020). Comunicado Técnico Diario Nuevo Coronavirus en el Mundo (COVID-19). 29 de febrero de 2020. México: Gobierno de México. Obtenido de: https://www.gob.mx/cms/uploads/attachment/file/538454/Comunicado_Tecnico_Diario_CO VID-19_2020.02.29.pdf

Tabla 1. Número de casos de Covid-19 en México de fecha 29 de febrero de 2020.

\begin{tabular}{llll} 
Entidad federativa & Muestras & Entidad federativa & Muestras \\
\hline Baja california & 2 & Michoacán & 18 \\
Baja california sur & 1 & Morelos & 1 \\
Ciudad de México & 11 & Nuevo León & 22 \\
Chiapas & 1 & Oaxaca & 3 \\
Coahuila & 1 & Puebla & 6 \\
Colima & 1 & Querétaro & 2 \\
Estado de México & 4 & San Luis Potosí & 1 \\
Guanajuato & 1 & Sinaloa & 9 \\
Guerrero & 1 & Tamaulipas & 1 \\
Hidalgo & 33 & Veracruz & 3 \\
Jalisco & 3 & & \\
\hline Total & & 125
\end{tabular}

Fuente: Gobierno de México. (2020). Comunicado Técnico Diario Nuevo Coronavirus en el Mundo (COVID-19). 29 de febrero de 2020. México: Gobierno de México. Obtenido de: https://www.gob.mx/cms/uploads/attachment/file/538454/Comunicado_Tecnico_Diario_CO VID-19_2020.02.29.pdf 
Figura 2. Número de casos de Covid-19 en México, por entidad federativa, de fecha 30 de septiembre de 2020.

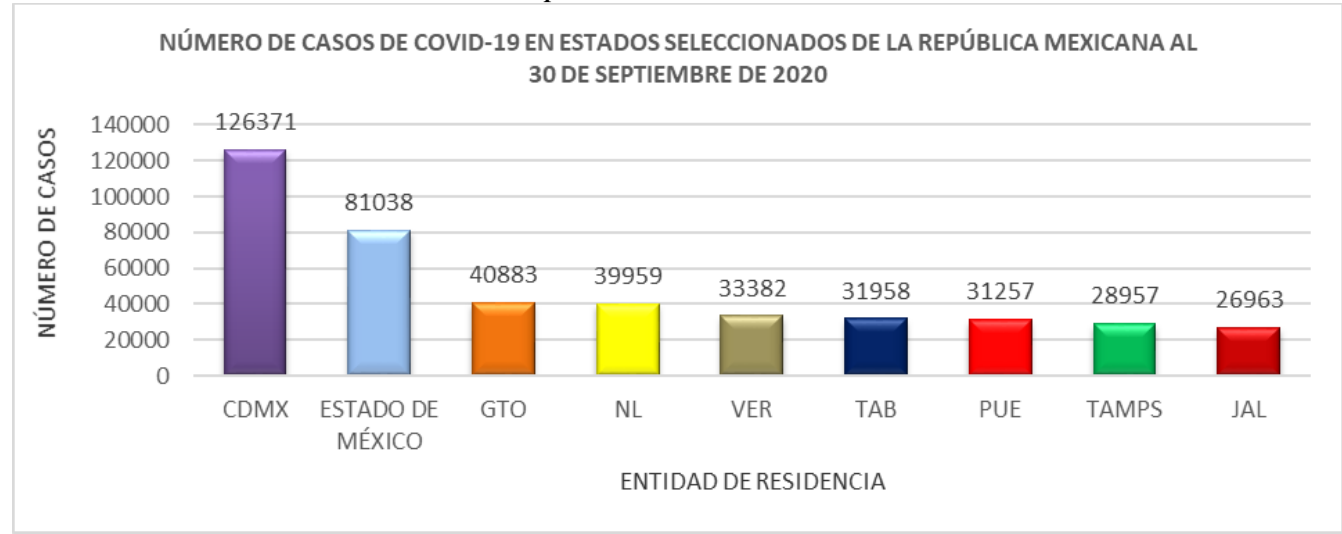

Fuente: Elaboración propia con datos del Gobierno de México. (2020). Informe Técnico Diario COVID-19 MÉXICO. 30 de septiembre del 2020. México: Gobierno de México. Obtenido de https://www.gob.mx/cms/uploads/attachment/file/581593/Comunicado_Tecnico_Diario_CO VID-19_2020.09.30_1_.pdf

\section{Recomendaciones para la población y las empresas en México}

Las recomendaciones generales y universales como higiene de manos frecuente con agua y jabón o soluciones base alcohol, consumir sólo alimentos bien cocinados y agua simple potable o embotellada, evitar el contacto con animales vivos o muertos, consumo de carne cruda y en lo posible evitar el contacto con personas enfermas. Evitar lugares concurridos o eventos donde asista un gran número de personas, utilizar el cubrebocas cubriendo su nariz y boca, evitar automedicarse. (Gobierno de México, 2020).

Para las empresas, negocios, puestos en mercados en tianguis, se deben seguir las mismas medias sanitarias, si quieren continuar con sus negocios abiertos.

\section{Recomendaciones a nivel internacional para apoyar a las empresas}

A nivel internacional la Comisión para América Latina y el Caribe (CEPAL) ha venido publicando una serie de documentos respecto a recomendaciones para que las empresas puedan enfrentar la crisis por la pandemia del Covid-19, en el documento: Sectores y empresas frente al COVID-19: emergencia y reactivación. (CEPAL, 2020), de fecha 2 de julio de 2020, se menciona, que la crisis golpea a una estructura productiva y empresarial débil, hay un riesgo de cambio estructural regresivo: reprimarización y cierre de más de 2,7 millones de empresas y pérdida de 8,5 millones de empleos en los próximos 6 meses, las políticas anunciadas: importantes, pero insuficientes, cambios en la organización de producción y las cadenas globales (CEPAL, 2020). 
Las cuatro propuestas de CEPAL son: 1. Extender los plazos de las medidas de apoyo a liquidez y al acceso al crédito. 2. Cofinanciamiento de nóminas salariales. 3. Transferencias en efectivo a trabajadores autónomos. 4. Apoyo a empresas de todo tamaño (CEPAL, 2020).

La destrucción de empresas y empleos en los próximos seis meses dice la CEPAL, será el cierre de 2,7 millones de empresas formales, de las cuales 2,6 millones son microempresas, pérdida de 8,5 millones de puestos de trabajo formales sólo por el cierre de empresas, los sectores más afectados: el comercio perderá 1,4 millones de empresas y 4 millones de puestos de trabajo formales, el turismo perderá por lo menos 290000 empresas y un millón de puestos de trabajo formales (CEPAL, 2020).

En las figuras 3 y 4 se reporta la situación en América Latina y el Caribe respecto a los sectores más afectados (CEPAL, 2020).

Figura 3. Comercio, algunos servicios y manufacturas que son los sectores más afectados por la pandemia del Covid-19, para 27 países seleccionados de América Latina y el Caribe, de fecha 2 de julio de 2020.

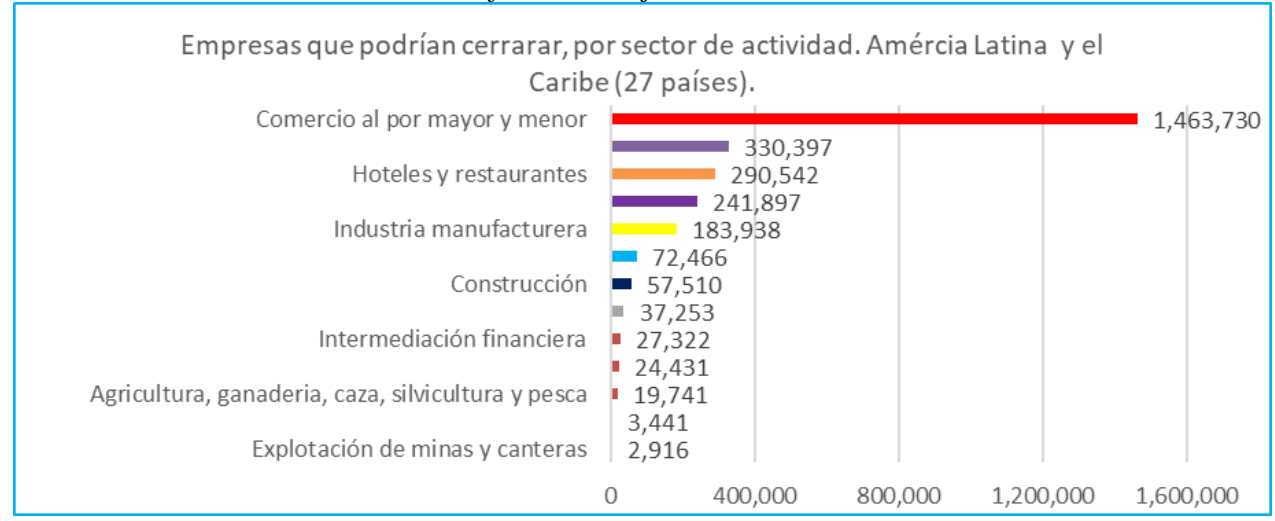

Fuente: CEPAL. (2020). Sectores y empresas frente al COVID-19: emergencia y reactivación. Santiago de Chile: CEPAL. Obtenido de https://www.cepal.org/sites/default/files/presentation/files/finalfinalde_la_crisis_a_la_reactivacion_ppt_-ab4.pdf 
Figura 4. Comercio, algunos servicios y manufacturas que son los sectores más afectados por la pandemia del Covid-19, para 27 países seleccionados de América Latina y el Caribe, de fecha 2 de julio de 2020.

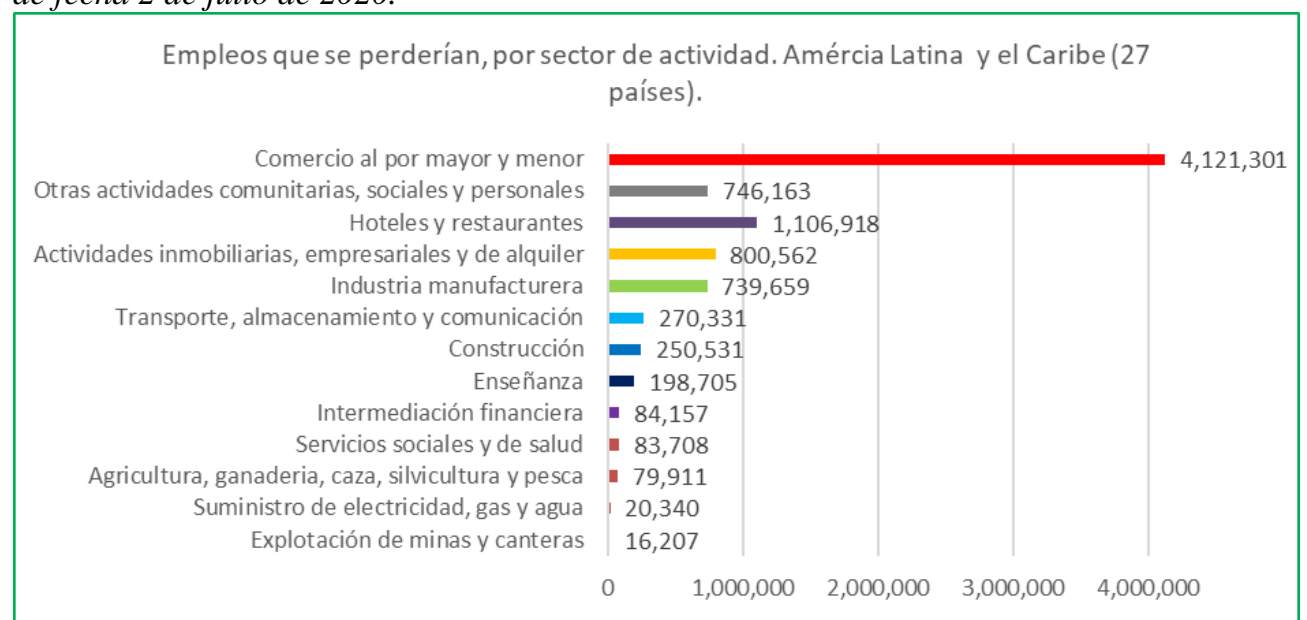

Fuente: CEPAL. (2020). Sectores y empresas frente al COVID-19: emergencia y reactivación. Santiago de Chile: CEPAL. Obtenido de https://www.cepal.org/sites/default/files/presentation/files/finalfinalde_la_crisis_a_la_reactivacion_ppt_-ab4.pdf

\section{Municipios de Ixtapaluca y Nezahualcóyotl en el Estado de México y Alcaldía de Iztapalapa en la Ciudad de México}

En la Figura 5 se muestra la ubicación de los Municipios de Ixtapaluca y Nezahualcóyotl del Estado de México y la Alcaldía Iztapalapa, en la Ciudad de México.

En la Tabla 2 se muestran los datos de población total de Ixtapaluca con 467,361 habitantes, Nezahualcóyotl 1,039,867 habitantes e Iztapalapa con 1,817,796 habitantes. Otro dato importante es la Población Económicamente Activa (PEA), con $52.8 \%, 59.9 \%$ y $54.9 \%$ respectivamente. Las unidades económicas registrado como el número de empresas son para Ixtapaluca 20,160, Nezahualcóyotl 49, 209 e Iztapalapa 132, 880. 
Figura 5. Ubicación del Municipio de Ixtapaluca, Nezahualcóyotl en el Estado de México y la Alcaldía de Iztapalapa en la Ciudad de México.

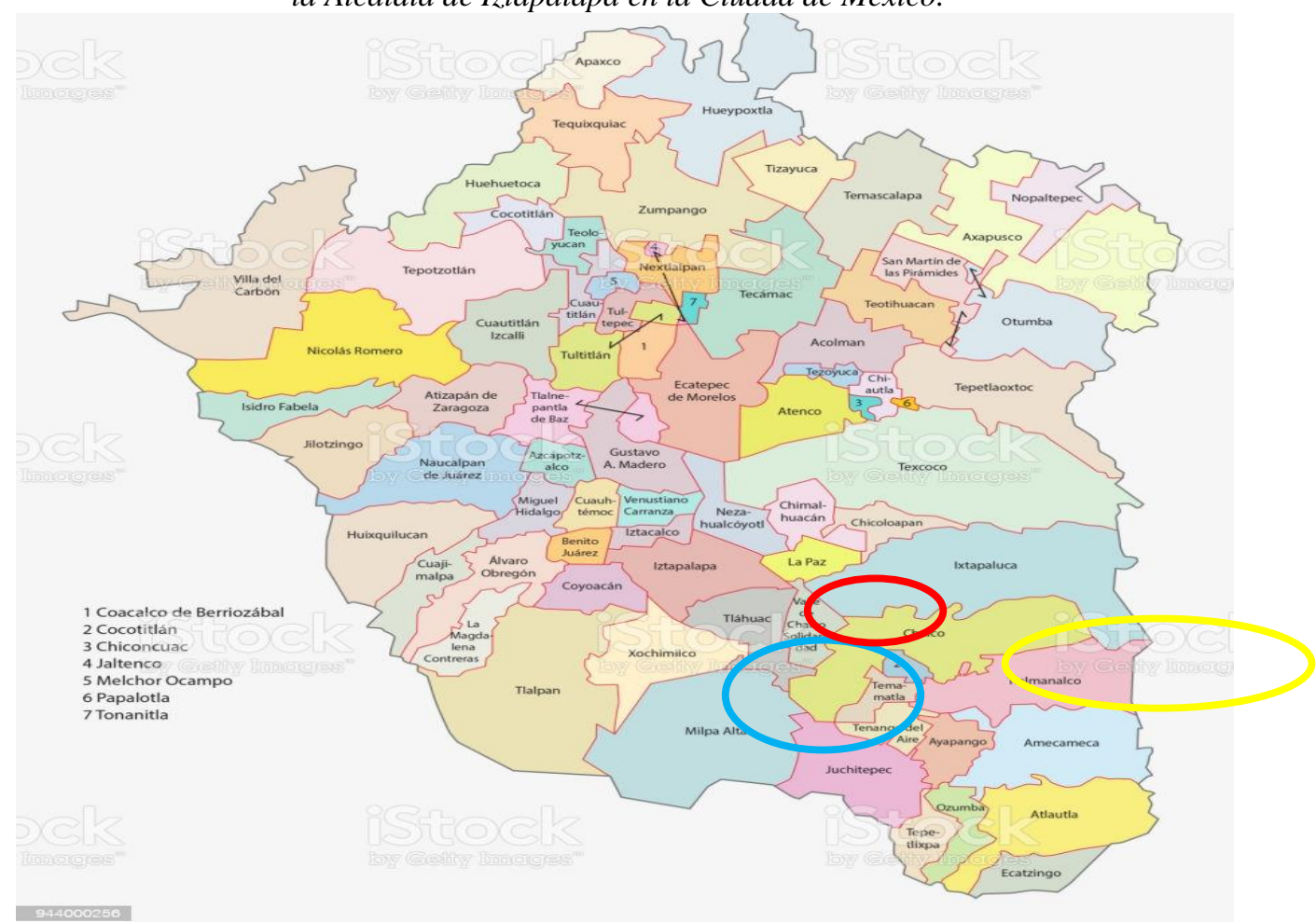

Fuente: Istockphoto. (2020). https://media.istockphoto.com/vectors/greater-mexico-citymap-vector-id 944000256

Tabla 2. Datos de población total, Población Económicamente Activa (PEA) y Unidades Económicas de Ixtapaluca, Nezahualcóyotl e Iztapalapa.

Ixtapaluca Nezahualcóyotl Iztapalapa

\begin{tabular}{llll}
\hline $\begin{array}{l}\text { Población } \\
\text { PEA }\end{array}$ & $567,361^{(1)}$ & $1,039,867^{(2)}$ & $1,817,796^{(3)}$ \\
$\begin{array}{l}\text { Total, } \\
\begin{array}{l}\text { unidades } \\
\text { económicas }\end{array}\end{array}$ & $20,160^{(7)}$ & $52.9 \%^{(5)}$ & $54.9 \%^{(6)}$ \\
\hline
\end{tabular}

Fuente: ${ }^{(1)}$ INEGI (2020). Datos para el Municipio de Ixtapaluca, año 2010.

${ }^{(2)}$ Datos para el Municipio de Nezahualcóyotl, año 2015.

(3) Datos para la Alcaldía Iztapalapa, año 2010.

(3) Datos para el Municipio de Ixtapaluca, año 2015.

${ }^{(5)}$ Datos para el Municipio de Nezahualcóyotl, año 2015.

(6) Datos para la Alcaldía Iztapalapa, año 2010.

(7) Datos para el Municipio de Nezahualcóyotl, año 2015.

${ }^{(8)}$ Datos para el Municipio de Ixtapaluca, año 2008.

(9) Datos para la Alcaldía Iztapalapa, año 2008. 


\section{Marco teórico}

Fischer (2017), menciona a Boone \& Kurtz, ellos definen al marketing como aquel que consiste en el desarrollo de una eficiente distribución de mercancías y servicios a determinados sectores del público consumidor, para Stanton, es el sistema global de actividades de negocios proyectados para planear, establecer el precio, promover y distribuir bienes y servicios que satisfacen deseos de clientes actuales y potenciales.

Mientras que Kotler (2003), lo define como aquella actividad humana dirigida a satisfacer necesidades, carencias y deseos a través de procesos de intercambio y para Fischer (2017), la mercadotecnia tiene como punto de partida determinar las necesidades y deseos del ser humano, se encarga de ofrecer productos y servicios. El marketing o la mercadotecnia, es una técnica que se realiza para cubrir las necesidades y deseos de los clientes, a través del uso de diferentes herramientas como pueden ser las variables de la mezcla de la mercadotecnia y la mezcla promocional, para que el cliente o consumidor puede obtener los productos y servicios deseados para su satisfacción.

De acuerdo con lo anterior, el marketing tiene diferentes áreas que deben ser estudiadas, conocidas y aplicadas como son, la administración de la mercadotecnia, el medio ambiente, los segmentos del mercado, la investigación de mercados, las estrategias del producto, precio, plaza o distribución, promoción, las ventas, el comportamiento del consumidor, tipos de marketing y/o mercadotecnia especializada (Fischer \& Espejo, 2017).

De especial interés para este trabajo es el concepto de marketing directo y digital, que consiste en las conexiones directas con consumidores individuales y comunidades de clientes, donde las empresas lo usan para diseñar ofertas y contenidos, el marketing directo usaba catálogos, por correo directo y telemarketing, se vendía por correo o por teléfono, mientras que con el uso de las tecnologías, ahora con los teléfonos inteligentes, tabletas y otros dispositivos digitales y todas las herramientas móviles en línea y de social media, ese marketing directo ha pasado a ser un marketing digital (Kotler, 2017).

El siguiente esquema muestra las formas que se usan cuando se habla de marketing directo tradicional y el marketing digital y de social media. 
Figura 6. Formas de marketing directo y digital.

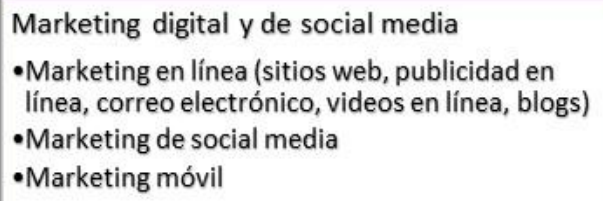

Fuente: Elaboración propia con datos de Kotler, P. (2017). Fundamentos de Marketing. México: Pearson.
Marketing directo tradicional

- Venta cara a cara

- Marketing por correo directo

- Marketing por catálogo

- Marketing por televisión de respuesta directa
- Telemarketing

- Marketing en quioscos

Dentro del marketing digital, se encuentran todas las estrategias mercadológicas llevadas a cabo a través de los medios digitales u on line, se reconoce que cada día van apareciendo nuevas formas de comercialización a través de los medios digítales. Los mercados que hoy compran por Internet lo hacen utilizando tecnologías que se iniciaron en la década de los 70as. El correo electrónico o e-mail tiene su origen en esos primeros inicios del Internet en 1985, en 1989 Tim Berners-Lee crea en Suiza la WWW, que son reglas que controlan las carpetas de archivos almacenadas en las computadoras. La aparición de buscadores, dan un mayor potencial mercadológico en la web, después aparecen las bandas anchas de acceso, que amplían la capacidad de transmisión de datos en gran volumen (Fischer \& Espejo, 2017).

También se agrega el concepto de mercadotecnia por internet que es el conjunto de actividades que permiten satisfacer las necesidades de un mercado bien definido que demanda productos y servicios a través de la World Wide Web (Fischer \& Espejo, 2017).

Para Fischer y Espejo (2017), existen diferentes formas en el comercio electrónico, que son todas las transacciones en internet que una organización realiza con sus mercados a través de cualquiera de los siguientes formatos: B2B, B2C, B2G, C2C, C2B, C2G, G2C, G2B, G2G. El Comercio electrónico inmediato, este se da cuando el pago se realiza directamente por medio del sistema electrónico (como el uso de PayPal o Amazon), mientras que el comercio electrónico mediato el pago, del bien o servicio adquirido cuando se realiza fuera del sistema electrónico (mediante pago de tarjetas). (Fischer y Espejo, 2017). Ver Figura 7 y 8. 
Figura 7. Formas del comercio electrónico.

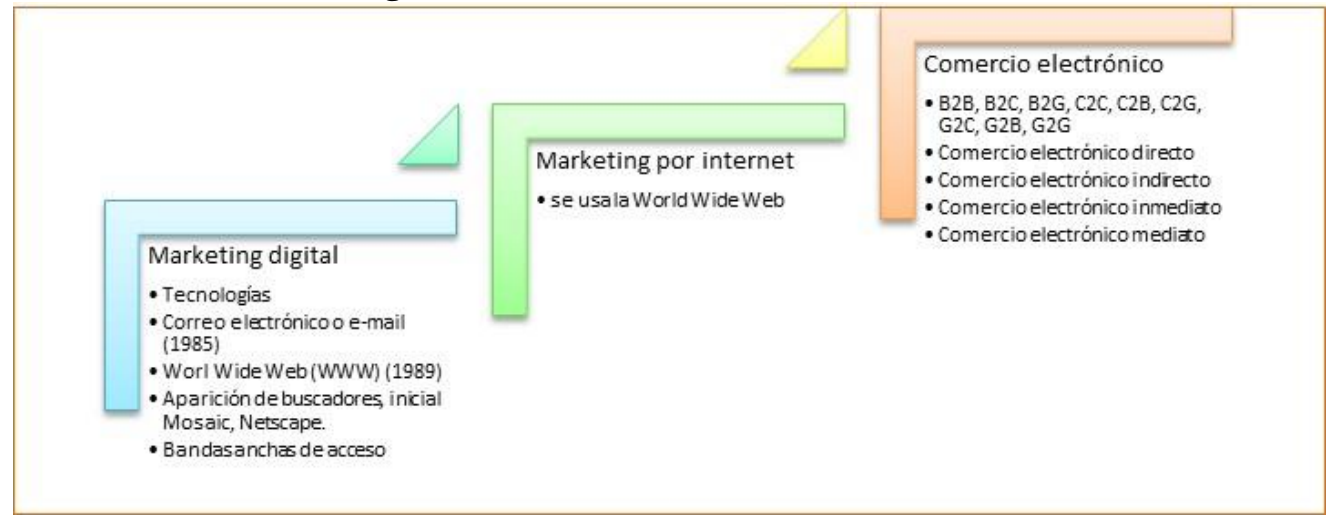

Fuente: elaboración propia con datos de Fischer, L., y Espejo, C. J. (2017). Mercadotecnia. México: Mc Graw Hill.

Figura 8. El comercio electrónico y sus diferentes formatos.

\begin{tabular}{|c|c|}
\hline Business to business & $\begin{array}{l}\text { B2B (business to busines o empresa a empresa), tipo de comercio electrónico que se refiere a las operaciones de } \\
\text { intercambio comercial entreempresas. }\end{array}$ \\
\hline \multirow[t]{2}{*}{ Busines to consumer } & $\begin{array}{l}\text { B2C (business to consumer o negocio a consumidor), sitio web tradicionala través del cual una empresa ofrece sus } \\
\text { productos y servicios a los consumidores. }\end{array}$ \\
\hline & B2G (busines to governmet, o negocio a gobierno), \\
\hline \multirow{3}{*}{$\begin{array}{l}\text { Consumer to } \\
\text { consumer }\end{array}$} & $\begin{array}{l}\mathrm{C2C} \text { (consumer to consumer o consumidor a consumidor), se da cuando un consumidor ofrece productos y servicios a } \\
\text { otros consumidores. }\end{array}$ \\
\hline & $\begin{array}{l}\text { C2G (consumer to government o consumidor a gobierno), se da cuando un gobierno describe en su sitio web } \\
\text { trámites v requerimientos que se deben cumplir con los productos v servicios públicos a disposicion de lo ciudadanos. }\end{array}$ \\
\hline & C2G (consumer to government o consu \\
\hline \multirow{3}{*}{$\begin{array}{l}\text { Gobernment to } \\
\text { consumer }\end{array}$} & G2C (governmenteto consumer gobierno a consumidor) \\
\hline & G2B (government to consumer o gobierno a negocio) \\
\hline & G2G (government to government o gobierno a gobierno) \\
\hline
\end{tabular}

Fuente: elaboración propia con datos de Fischer, L., y Espejo, C. J. (2017). Mercadotecnia. México: Mc Graw Hill.

Otro término que se está usando para estos temas es el llamado Marketing en redes sociales (MRS), que permiten generar conciencia y aprecio acerca de los productos y servicios de la empresa. Las redes sociales digitales son plataformas donde se publica y comparte, con clientes y prospectos, contenido en el formato de texto, audio, video, fotografía y multimedia. Existen muchas redes sociales disponibles en la web y para llegar a una estrategia efectiva, las diversas plataformas deben ser revisadas y evaluadas a fin de seleccionar las más adecuadas (Fischer \& Espejo, 2017).

También lo llaman Social media o medios sociales que son un grupo de plataformas en internet que facilitan la edición, publicación e intercambio 
de información, a través de estas plataformas masivas, estos se basan en la influencia y la interacción entre una audiencia pública que es cada vez más participativa. Los medios sociales son un conjunto de plataformas digitales que amplifican el impacto del voz a voz; además, de ser medible y rentabilízale por la mercadotecnia. Ver Figura 9. (https://yiminshum.com/social-media-mexico-2020/).

Finalmente se presentan los siguientes resultados de una encuesta realizada por Cocktailmarketing. Enero de 2020, que son uno de los puntos que se deberán comprobar en posteriores investigaciones, pero que hoy nos permiten ver el comportamiento del marketing digital, social media. Ver Figura 10.

Figura 9. Social media o medios sociales.

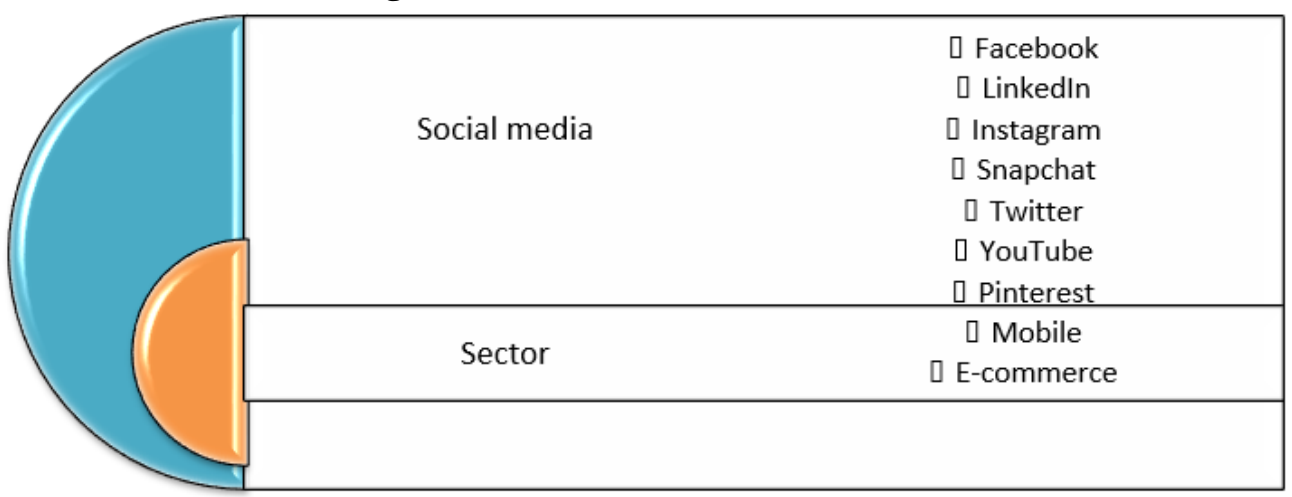

Fuente: elaboración propia con datos de https://yiminshum.com/social-media-mexico2020/). 
Figura 10. Encuesta realizada por la Agencia de Marketing Digital: ocktailmarketing, para

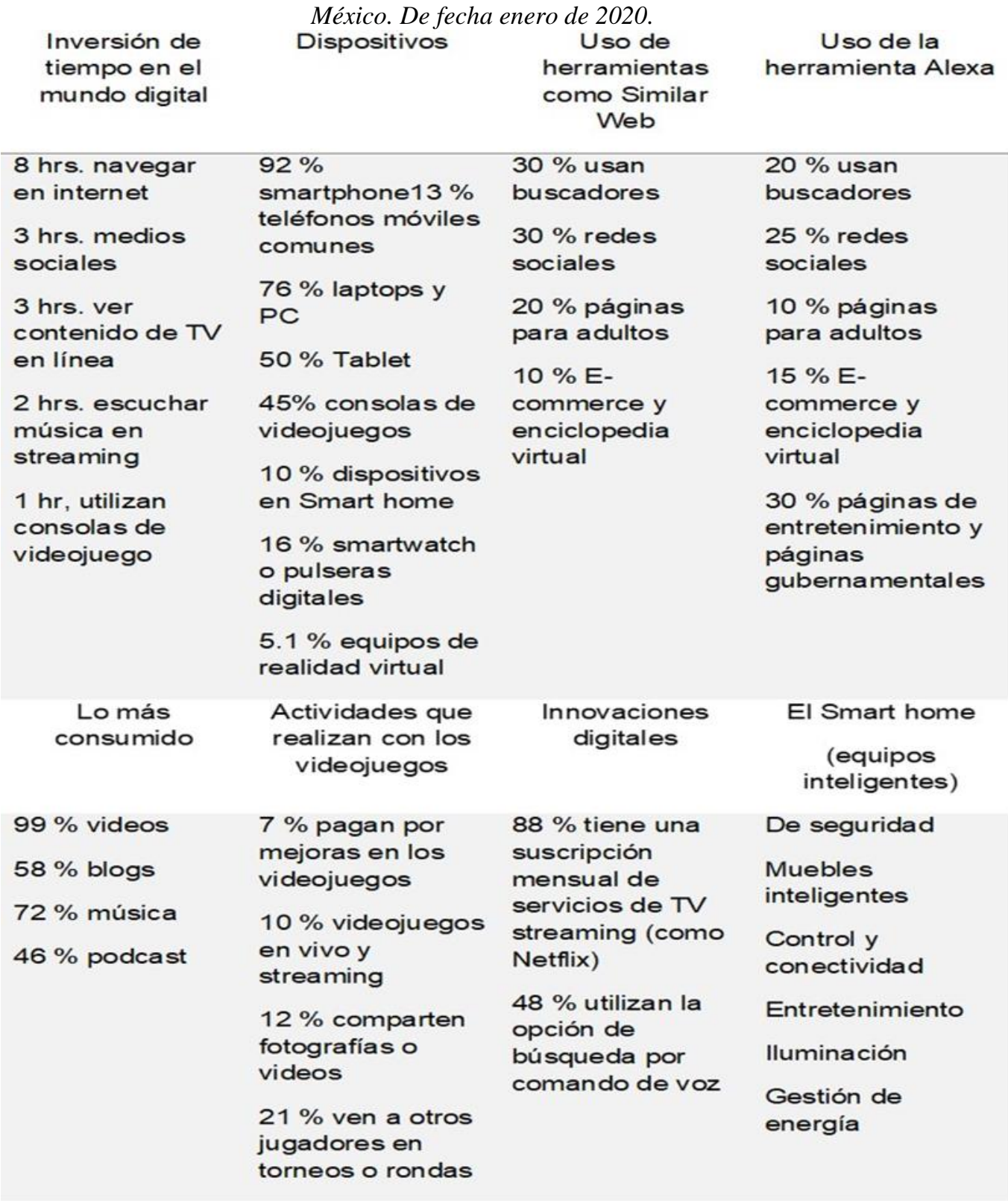




\section{Plataformas más utilizadas (como redes sociales)}

$94 \%$ Facebook
$89 \%$ WhatsApp
$78 \%$ FB
Messenger
$71 \%$ Instagram
$61 \%$ Twitter
$46 \%$ Pinterest
$36 \%$ Linkedln
$35 \%$ Snapchat
$32 \%$ Skype
$22 \%$ Tumblr
$22 \%$ Twitch
$21 \%$ WeChat
$20 \%$ Tik Tok
$17 \%$ Reddit
$16 \%$ Line
Categorías que
más compran

Hospedajes
Productos
electrónicos
Moda y belleza
Juguetes,
hobbies y DIY
Muebles

$\begin{array}{ll}\begin{array}{l}98 \% \text { redes } \\ \text { sociales }\end{array} & \begin{array}{l}50 \% \text { búsqueda } \\ \text { de imágenes }\end{array} \\ \begin{array}{l}97 \% \text { mensajería } \\ \text { instantánea o } \\ \text { chat }\end{array} & \begin{array}{l}44 \% \text { consumen } \\ \text { contenido } \\ \text { audiovisual o TV } \\ \text { streaming }\end{array} \\ \begin{array}{l}91 \% \\ \text { entretenimientos } \\ \text { y videos }\end{array} & \begin{array}{l}43 \% \text { transferir } \\ \text { dinero }\end{array} \\ 85 \% \text { mapas y } & \begin{array}{l}38 \% \text { scanear el } \\ \text { código QR }\end{array} \\ \text { ubicaciones } & 18 \% \text { boarding } \\ 73 \% \text { música } & \text { pass } \\ 69 \% \text { compras } & \end{array}$

$62 \%$ videojuegos

$45 \%$ bancarias

$30 \%$ de salud y

fitness

$12 \%$ de citas y

amistad

Figura 10 (continuación)

aplicaciones

Uso de los

equipos móviles

Actividades
relacionadas con
el E-commerce

$89 \%$ opciones

para satisfacer

necesidades

$89 \%$ productos y

servicios que

quieren comprar

$91 \%$ visitan páginas en líneas retail

$67 \%$ adquieren productos esperando las fechas como buen fin

$40 \%$ compran $\mathrm{PC}$

$44 \%$ compran dispositivos móviles

$$
\begin{array}{cc}
\text { Métodos } & \text { Las empresas ocupan } \\
\text { para } & \text { comolugares para su } \\
\text { comprar } & \text { publicidad }
\end{array}
$$

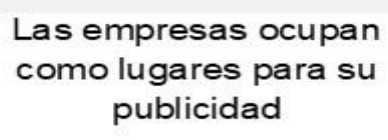
como lugares para su publicidad

$40 \%$ tarjetas de crédito

$26 \%$ efectivo $15 \%$ wallet electrónico $3 \%$ otros
$42 \%$ publicidad en social media

$38 \%$ motores de búsqueda $36 \%$ publicidad en TV $35 \%$ recomendación en WOM Perfil del usuario:
edad y género

13 a $17 \quad 3.5 \% \mathrm{M}$ $6.6 \%$

\begin{tabular}{ll}
\hline 18 a 24 & $3.1 \% \mathrm{H}$ \\
\hline $26.8 \%$ & $13.4 \% \mathrm{M}$ \\
\hline 25 a 34 & $13.4 \% \mathrm{H}$ \\
\hline $15.6 \%$ & $15.6 \% \mathrm{M}$ \\
& $15.6 \% \mathrm{H}$
\end{tabular}

Fuente: tomado de la página https://cocktailmarketing.com.mx/estadisticas-de-redes-sociales/

\section{Método}

El trabajo presenta dos resultados, por lo que, en la primera parte, se usa el método cuantitativo, se presentan algunos de los resultados de la encuesta que se aplicó para conocer el uso de las Apps antes de iniciar la 
pandemia del Covid-19 y durante esta, la encuesta se aplicó online usando Google forms, cuestionario con 37 preguntas de tipo preguntas cerradas de opción múltiple, selección de casillas y de respuesta corta. El cuestionario se aplicó a través del link https://forms.gle/tKfkhAxgDvC1N7q68, durante el periodo del 10 al 12 de julio del 2020, se trabajó con 78 cuestionarios que fueron devueltos, aplicado a jóvenes de entre 17 a 30 años que residen en el Municipio de Nezahualcóyotl, estudiantes principalmente y de NSE entre C+ y D+.

En la segunda parte se utiliza el método descriptivo a través de la observación y la recolección de imágenes y fotografías de las estrategias que se usaron para enfrentar la pandemia del Covid-19. Las empresas y negocios que se ejemplifican se encuentran en los Municipios de Ixtapaluca y de Nezahualcóyotl, ubicados al oriente del Estado de México y la Alcaldía de Iztapalapa en la Ciudad de México. El periodo de levantamiento de información se realizó del 19 de marzo al 30 de septiembre de 2020.

Como objetivos generales se tienen: conocer las estrategias mercadológicas, específicamente del marketing directo y digital, que usan las empresas de los Municipios de Ixtapaluca y Nezahualcóyotl ubicados en el oriente del Estado de México y la Alcaldía de Iztapalapa en la Ciudad de México para enfrentar la Pandemia del Covid-19 y el segundo es conocer las Apps que se usaban antes y durante la pandemia.

Las preguntas de investigación que se pretende responder son: ¿Cuáles son las estrategias mercadológicas que han usado las empresas para enfrentar la pandemia del Covid-19? y la segunda ¿Cuáles son las App que han usado los estudiantes antes y durante la Pandemia del Covid-19, que es un sentir de la sociedad?

\section{Hallazgos}

En esta sección se presentan los principales hallazgos divido en resultados de la encuesta sobre las Apps y de las diferentes herramientas que se fueron usando por los negocios, junto con las evidencias de estos.

Principales resultados de la encuesta

De acuerdo con la encuesta que se aplicó, los grandes resultados se mencionan enseguida, los entrevistados mencionaron que el $91 \%$ de las personas cuentan con Wifi en casa. El 58\% de las personas ocupan datos móviles para navegar. Respecto a las compañías que ofrecen Internet, los resultados fueron que el $41 \%$ de las personas compran el servicio a la empresa Telcel, $25 \%$ a la empresa AT\&T, 18\% Movistar, $14 \%$ Unefón. El 56\% menciona que compran un plan móvil. 
Antes de la Pandemia no se descargaban tantas aplicaciones, y durante la Pandemia las personas descargaron más de tres aplicaciones por mes. Las aplicaciones antes de la Pandemia se usaban más para entretenimiento y para socializar. Mientras que durante la Pandemia las aplicaciones que se descargaron fueron con la finalidad de usarse para su trabajo y educación. Para la educación se mencionaron las aplicaciones de Microsoft Teams, Classrom y Zoom.

Las descargas se realizan usando principalmente Play Store en un 80 $\%$, seguido de App Store, con un 11\%. El $59 \%$ durante la pandemia está usando las Apps de transporte como Uber y Didi. Respecto al comercio, se reporta que la aplicación de Mercado libre, seguida por Shein y después Uber eats, son las más usadas durante la pandemia.

De acuerdo con los datos obtenidos se puede identificar que antes de la Pandemia la aplicación bancaria que más se utilizaba era la de BBVA con un porcentaje del 40\%, seguido de Banco Azteca con un porcentaje del 33\%. En comparación con las utilizadas durante la Pandemia, estas han seguido siendo las más usadas. En las figuras 11, 12 y 13 se muestran estos resultados.

Figura 11. Apps nuevas, que se han utilizado durante la Pandemia del Covid-19.

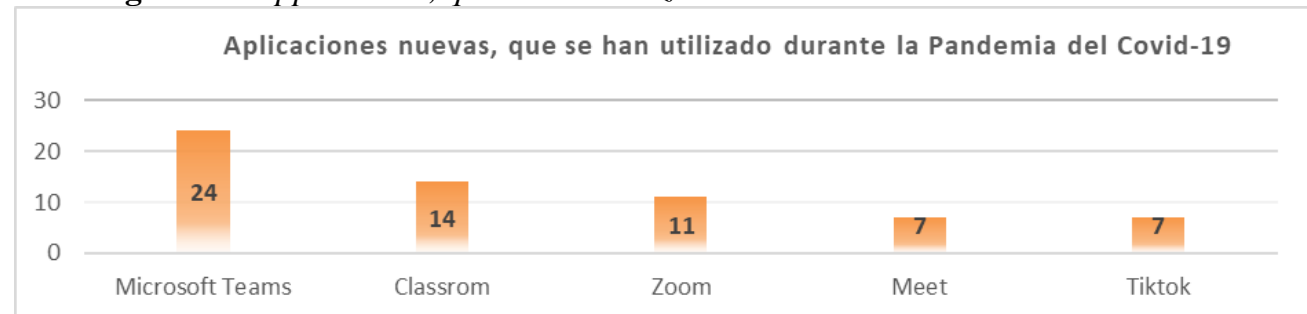

Fuente: elaboración propia con datos de la encuesta aplicada. T.S.U. Miriam Ramírez Martínez.

Figura 12. Apps usadas para realizar compras durante la Pandemia del Covid-19.

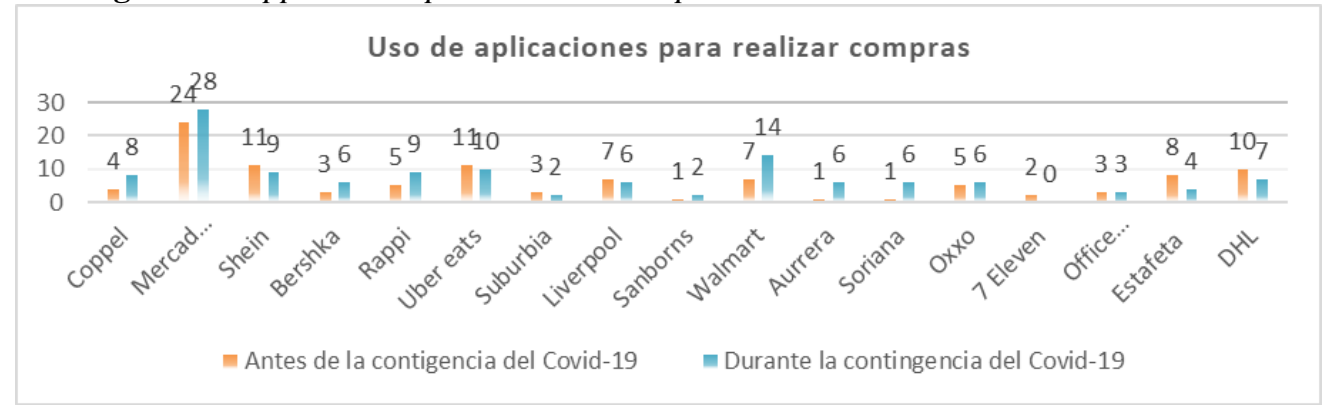

Fuente: elaboración propia con datos de la encuesta aplicada. T.S.U. Miriam Ramírez Martínez. 
Figura 13. Apps bancarias usadas durante la Pandemia del Covid-19.

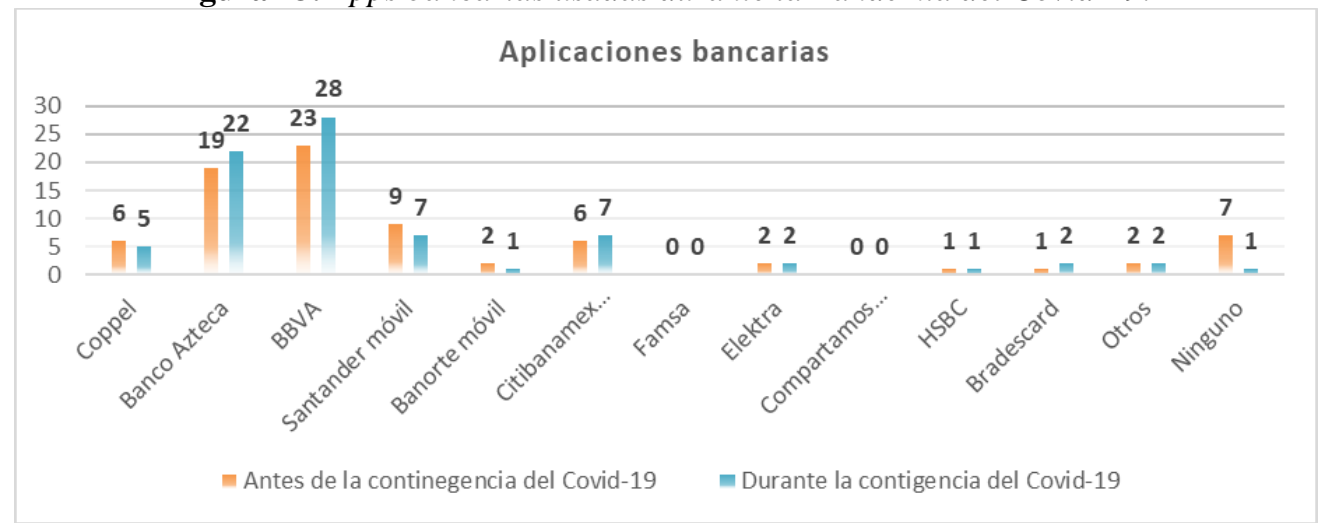

Fuente: elaboración propia con datos de la encuesta aplicada. T.S.U. Miriam Ramírez Martínez.

\section{Estrategias mercadológicas usadas por las empresas}

Las empresas realizaron como estrategias mercadológicas, las redes sociales, esa fue su mejor estrategia para enfrentar la Pandemia, se identifican básicamente el uso del Mobile o celular personal, que fue lo de más inmediatez, usando las Apps o aplicaciones como el WhatsApp, principalmente, el Facebook fue fundamental para realizar ventas inmediatas, el envío a domicilio de productos y de realizar servicios

Las empresas que se dio seguimiento en su comportamiento para enfrentar la pandemia son: Microempresas: papelerías, farmacias, tiendas de abarrotes (conocidas como la tiendita de la esquina, del barrio), tortillerías, puestos del tianguis y mercados. Empresas medianas y grandes: El Oxxo, Concord, Viky Form, Cinepolis, Plazas y/o centros comerciales como Walmart, Soriana, Aurrera, Price Shoes, empresas mayoristas como El puma abarrotero, Estafeta, Interjet, AT\&T, laboratorios OLAB, Azteca, salud digna,

Ver en las siguientes tablas 3 a 12, donde aparecen las imágenes y fotografías que muestras las estrategias mercadológicas que se han usado durante la Pandemia del Covid-19

1. Usar las recomendaciones del gobierno, slogan \#quedate en casa

2. Uso de catálogos en línea, digitales, catálogos web, llegaron para quedarse

3. Slogans creados por las empresas para mantenerse en la mente del consumidor

4. Envió por mensajería, hasta donde funcionó y funciona

5. Medidas de regreso a sucursales

6. Productos nuevos, en su portafolio de productos y/o servicios 
Productos para la Pandemia del Covid-19

7. Los asistentes virtuales

8. Páginas en internet, con mejores diseños

9. Uso de call centers

10. Promociones de venta para vendedores

11. Promociones de venta para consumidores

12. Creación de blogs

13. Redes sociales: Facebook, twitter, Instagram, videos you tube, wish, Messenger,

14. Las Apps que más se han utilizado en tiempos de pandemia.

15. El gobierno municipal uso espectaculares, carteles, lonas,

16. Respecto a los servicios, en educación, capacitación, el uso de webinar a través de diversas plataformas: Zoom, Go To Meeting, Go To Webinar, Classroom

17. Los memes se multiplicaron

18. Los días de mayores ventas, día del niño, día de la madre, día del padre, 15 de septiembre, se celebraron desde casa

19. El uso del código QR, sector restaurantero

20. Sus efectos en el comportamiento del consumidor, respecto a las empresas: Comen más verduras, comen más saludable, les gusta estar en casa y que les lleven los productos y servicios hasta su domicilio, los hace sentir seguros, toman las medidas en casa, como usar el cubrebocas, la mascarilla, el tapete sanitizado, el gel y aerosol para limpiar y desinfectar.

21. Medidas sanitarias

22. Información estatal para poder hacer la reapertura de negocios

23. Uso de plástico, acrílico, entrega de gel, exigir el uso de cubrebocas, cintas para marcas los accesos de entrada y salida, restricción de horarios, para atender al consumidor 
Special Edition: Gestión de la mercadotecnia en latinoamérica en tiempos de COVID-19

Tabla 3. Fotografías y evidencias del uso de redes sociales.

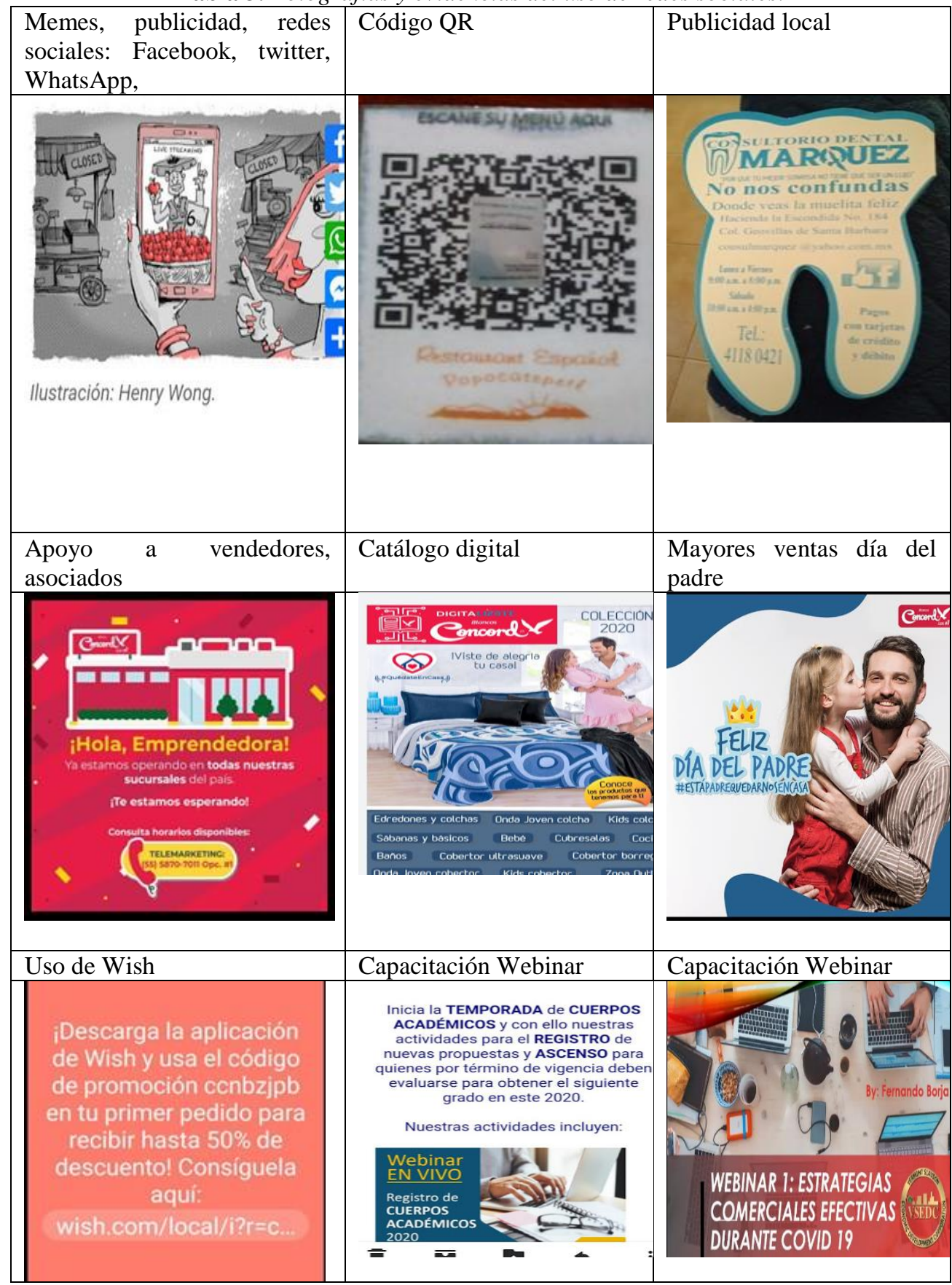

Fuente: Fotografías tomadas de empresas, Colchas México, S.A. de C.V.; Vicky Form, S.A. de C.V.; Empresa Copy color; Distinción académica. 
Special Edition: Gestión de la mercadotecnia en latinoamérica en tiempos de COVID-19

Tabla 4. Fotografías y evidencias del uso de redes sociales.

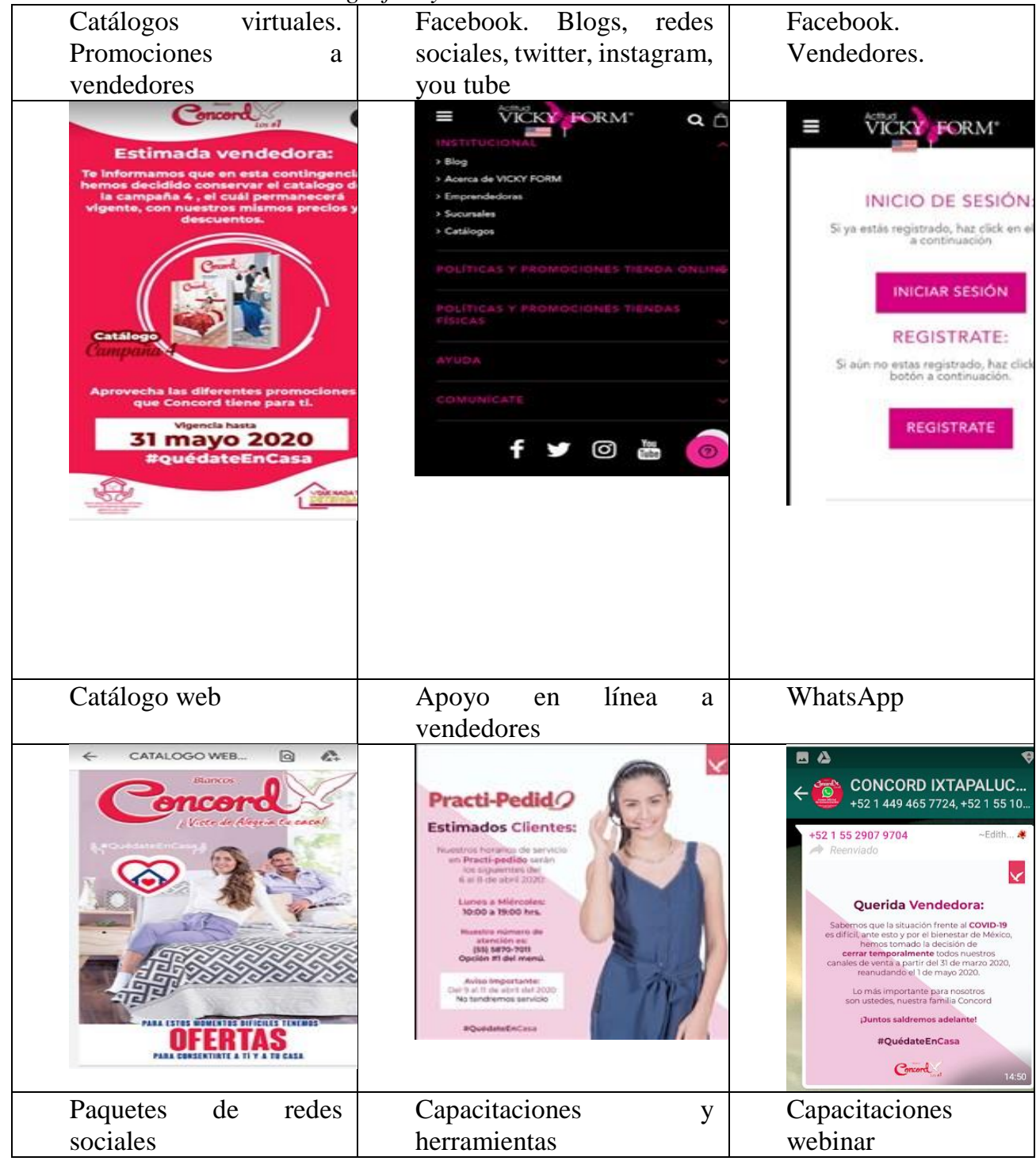



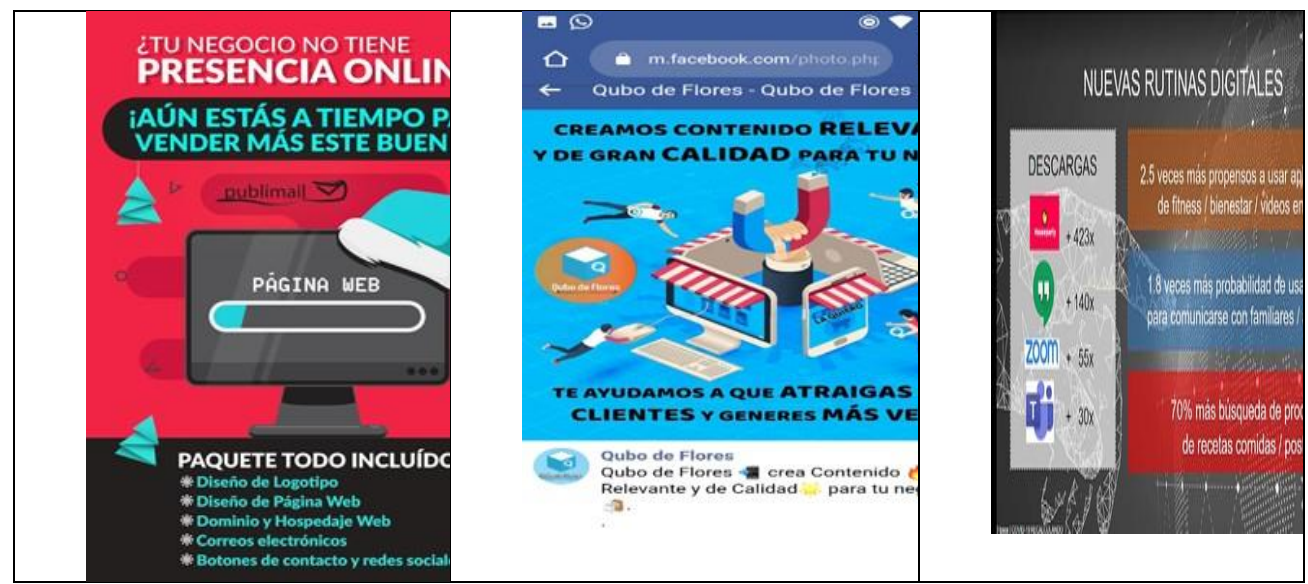

Fuente: Fotografías tomadas de empresas, Colchas México, S.A. de C.V.; Vicky Form, S.A. de C.V.; Empresa Copy color; Distinción académica, Qubo.

Tabla 5. Fotografías y evidencias. Apoyo a vendedores.

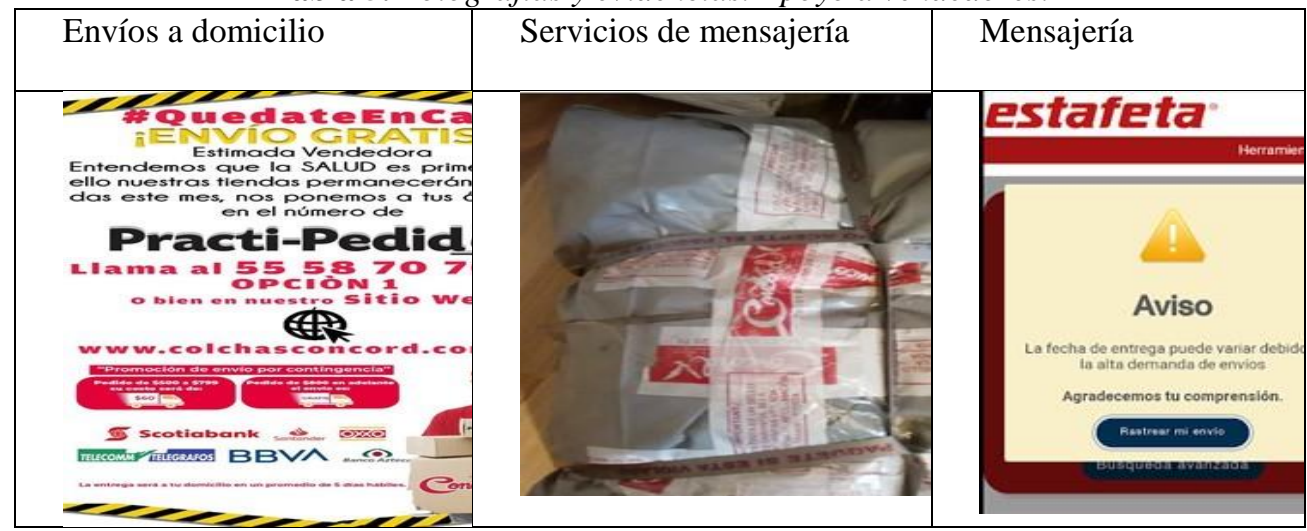

Fuente: Fotografías tomadas de empresas, Colchas México, S.A. de C.V.; Estafeta, Carga Aérea, S.A. de C. V.

Tabla 6. Fotografías y evidencias. Catálogos virtuales, WhatsApp, Asistente virtual.

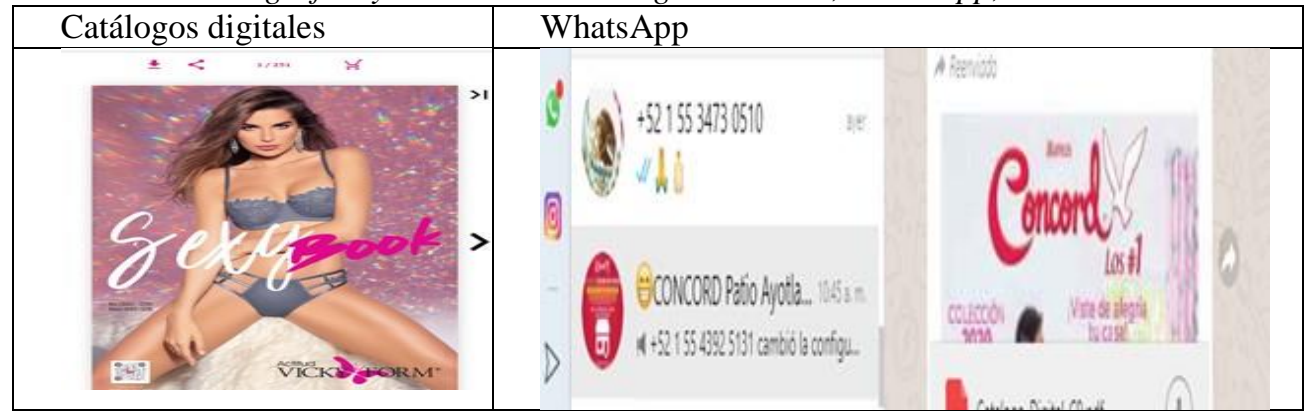




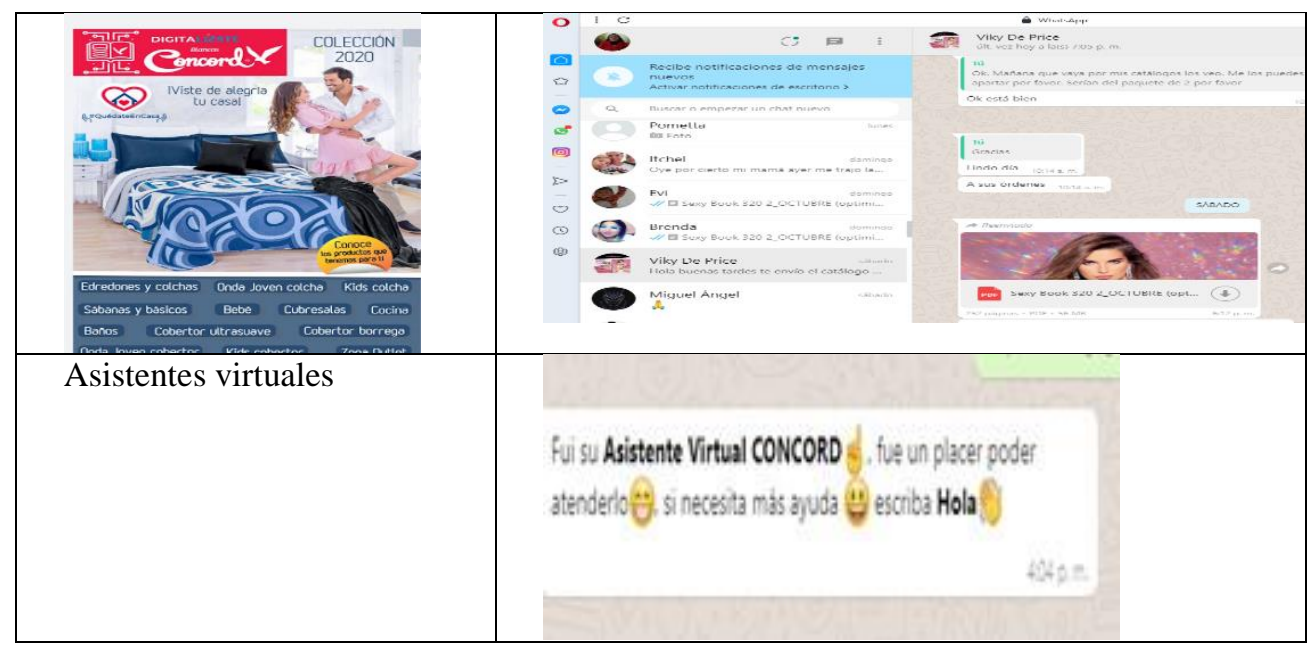

Fuente: Fotografías tomadas de empresas, Colchas México, S.A. de C.V.; Vicky Form, S.A. de C.V.

Tabla 7. Fotografías y evidencias del uso de redes sociales. Promociones a vendedores.

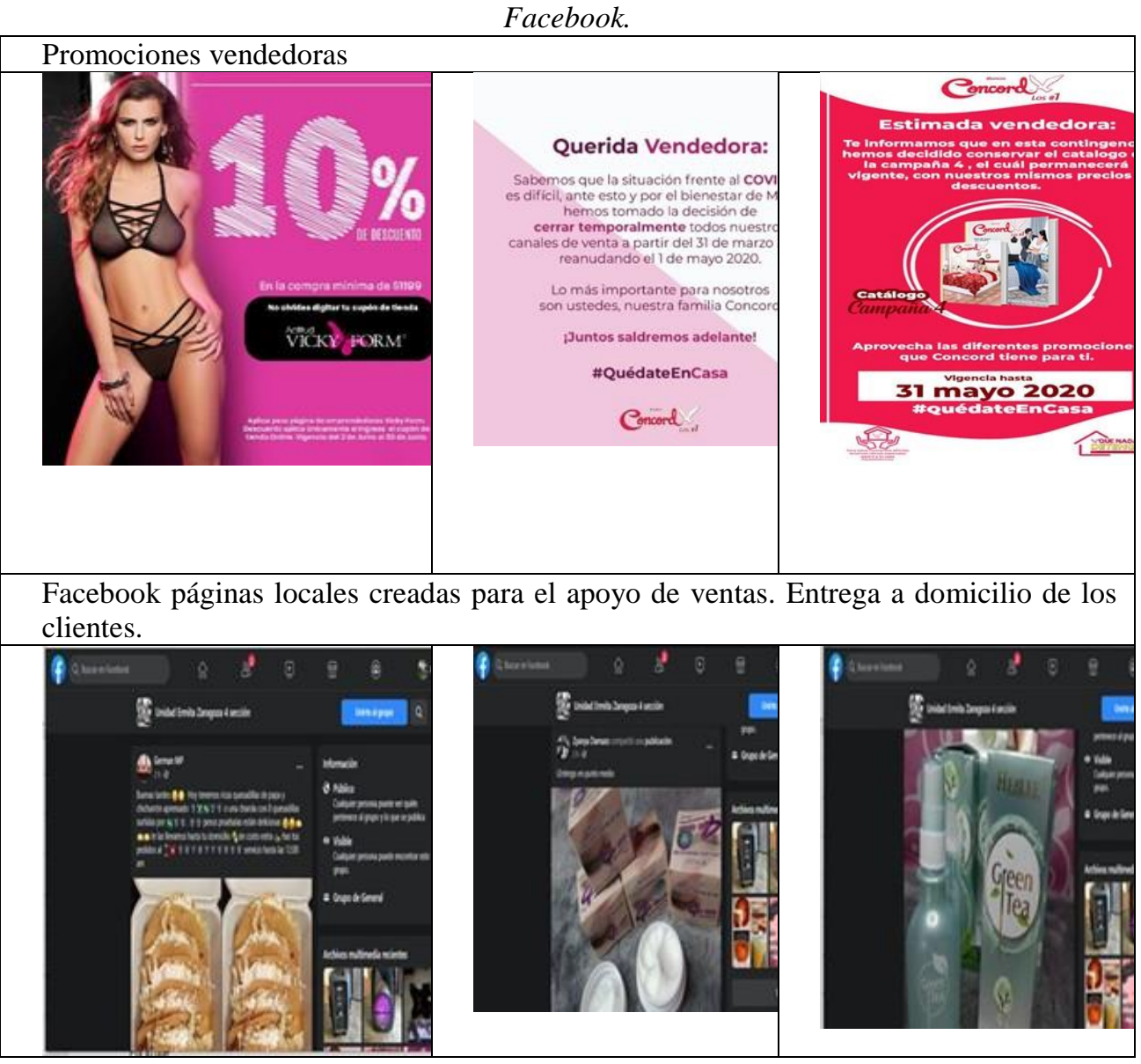




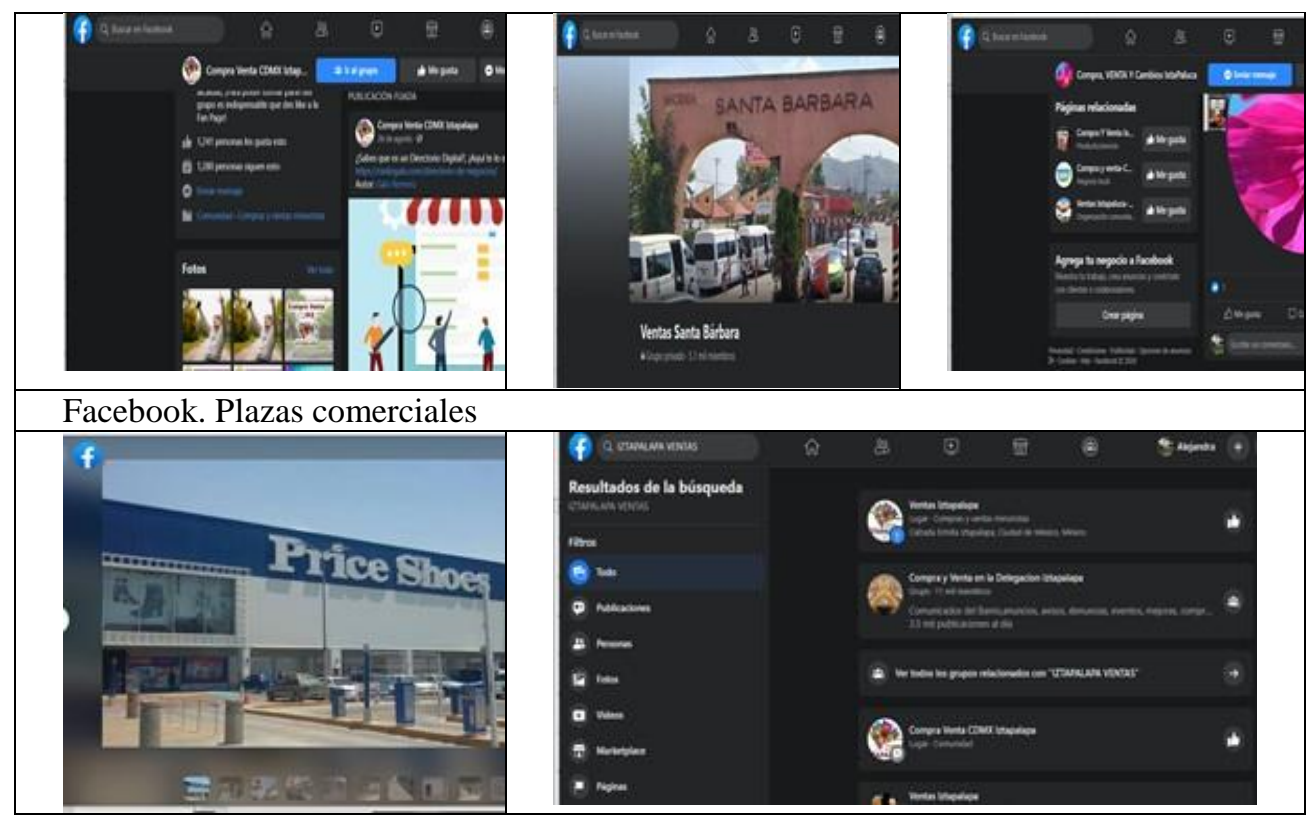

Fuente: Fotografías tomadas de empresas, Colchas México, S.A. de C.V.; Páginas de Facebook, Ixtapaluca, Iztapalapa.

Tabla 8. Productos adecuados a las necesidades.

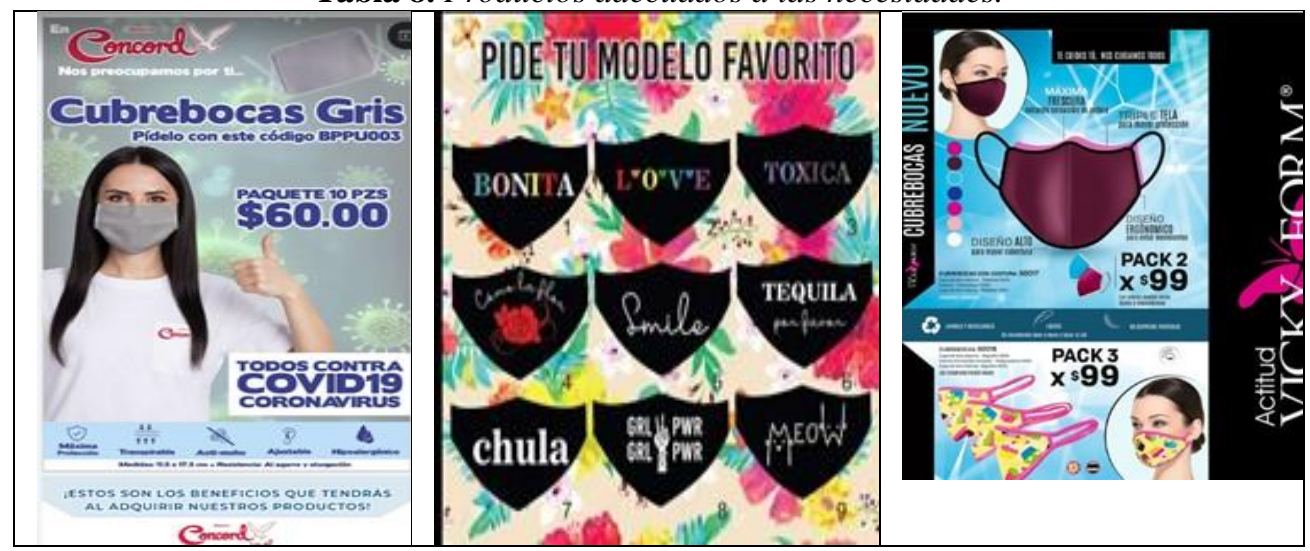

Fuente: Fotografías tomadas de empresas, Colchas México, S.A. de C.V.; Vicky Form, S.A. de C.V.; Empresa Copy color. 
Special Edition: Gestión de la mercadotecnia en latinoamérica en tiempos de COVID-19

Tabla 9. Medidas sanitarias. Propaganda.

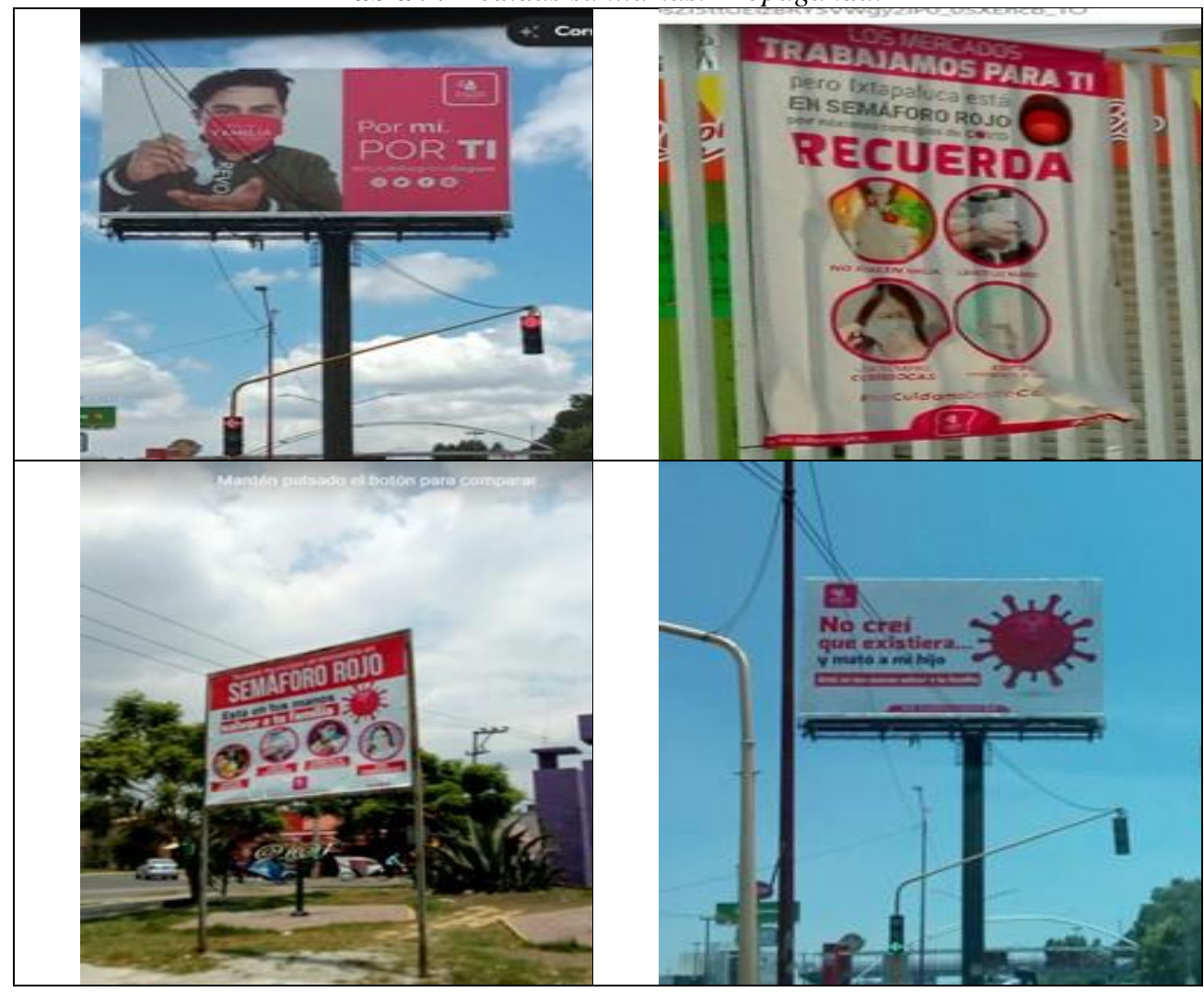

Fuente: Fotografías tomadas de los gobiernos municipales.

Tabla 10. Medidas sanitarias en tianguis, uso de gel y sana distancia. En establecimientos.

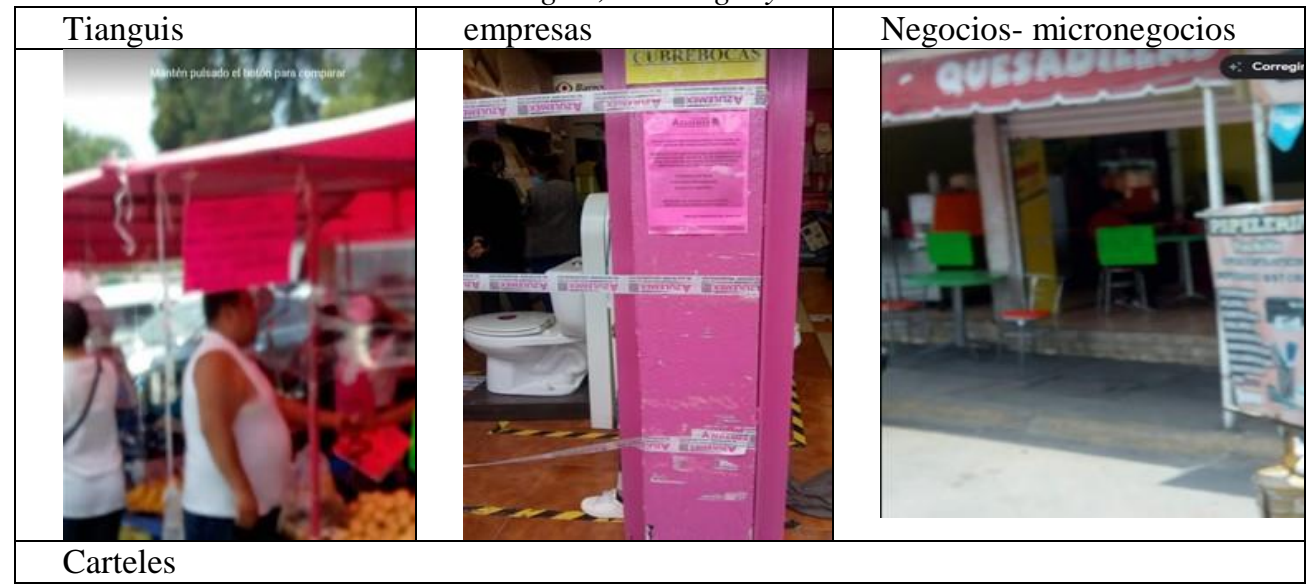




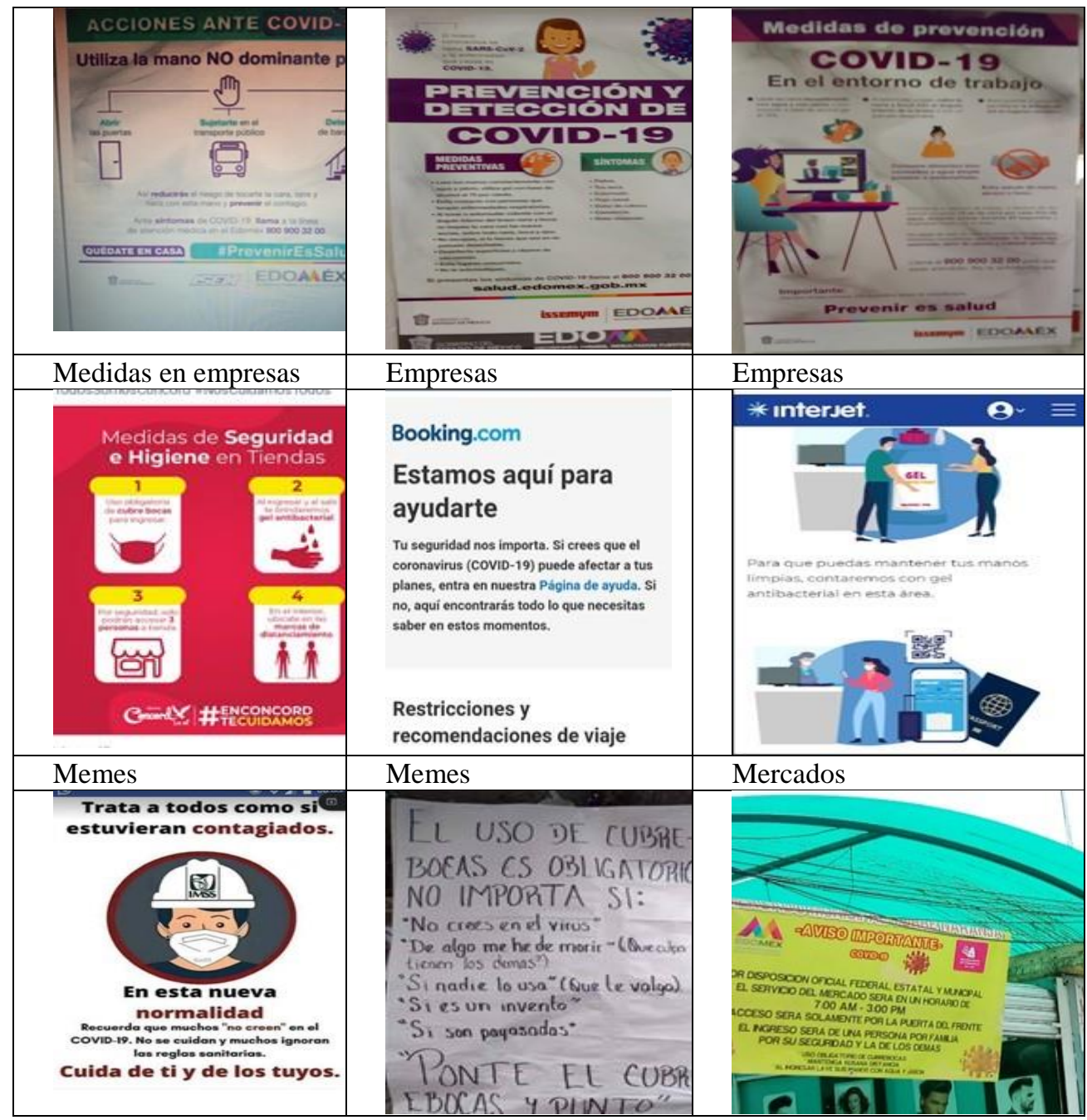

Fuente: Fotografías tomadas de varios, lugares, empresas Booking, Interjet, Gobierno Municipal del Estado de México, Gobierno del Estado de México.

Tabla 11. El regreso seguro.

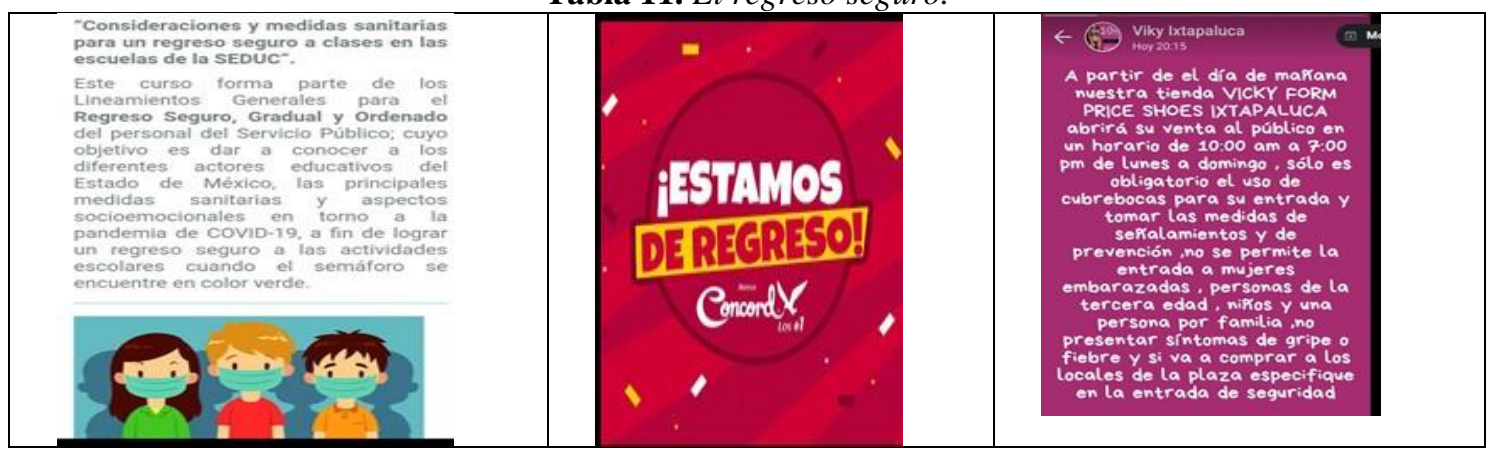




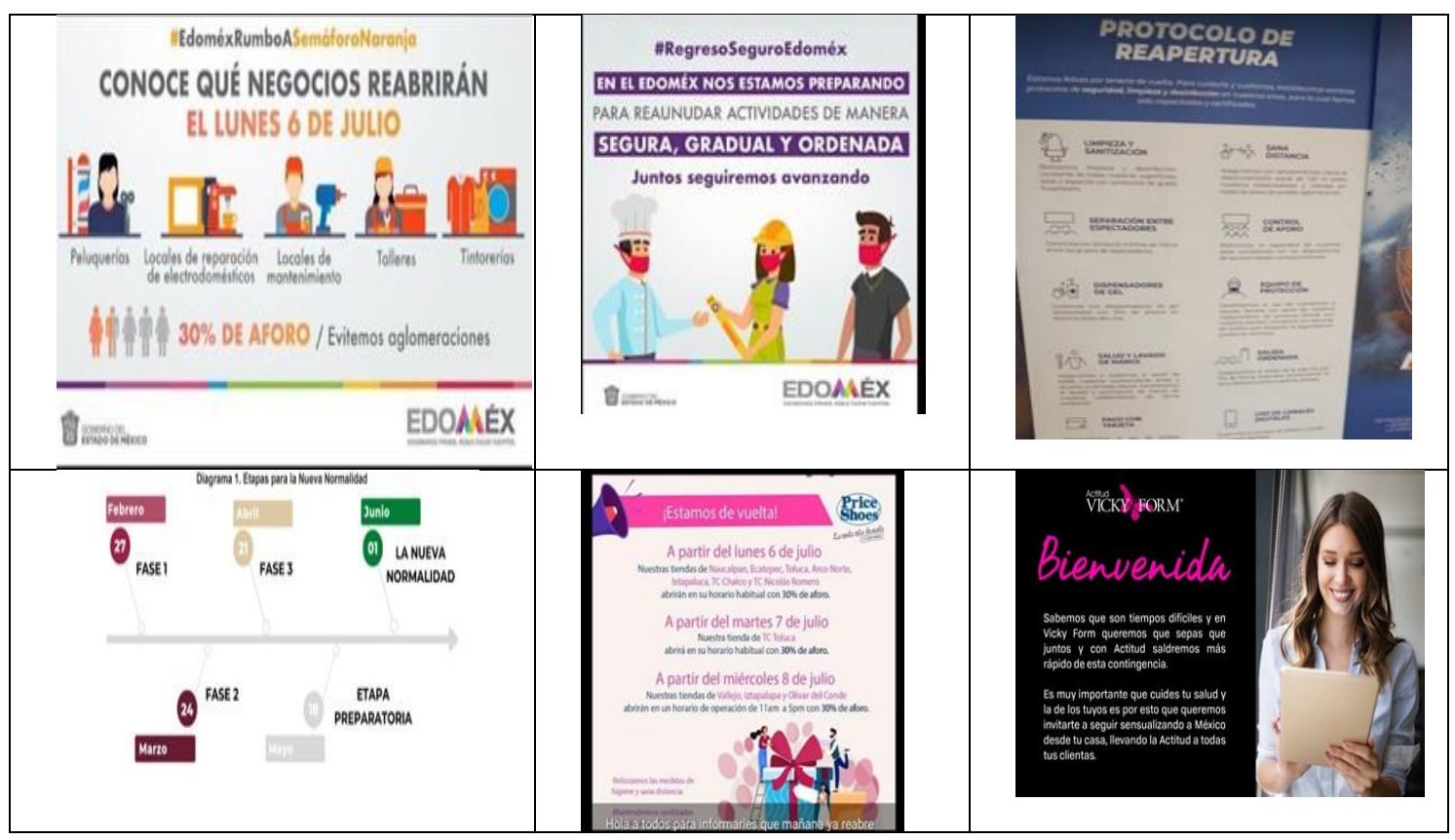

Fuente: Fotografías tomadas de empresas, Colchas México, S.A. de C.V.; Vicky Form, S.A. de C.V.; Gobierno del Estado de México, Gobierno de la Ciudad de México, Cinépolis, S.A. de C.V.

Tabla 12. Las que no sobrevivieron. Locales comerciales solamente.

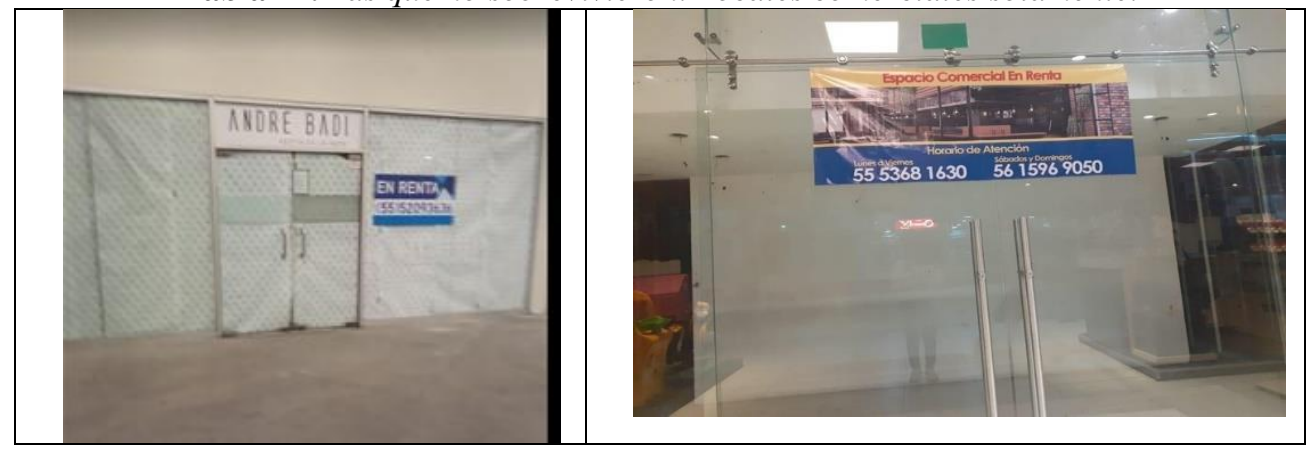

Fuente: André Badi, S.A. de C.V. sucursal local comercial. Intima, S.A. de C.V. sucursal local comercial.

\section{Discusión}

Sabemos que la Pandemia del Covid-19, no va a terminar tan pronto, por lo que las medidas sanitarias deben seguir; sin embargo, resulta necesario que la economía no se detenga, ya que, detrás de las empresas, se encuentran la población, los trabajadores, inmersos en un ciclo económico y comercial que no puede esperar. En función de lo anterior, el uso de las herramientas del marketing digital ofrece soluciones efectivamente en el desarrollo y crecimiento de las empresas y por ende del país. 
Cuestiones que quedan pendientes, es preguntar a la sociedad, actualizar cifras y datos para tener mayores propuestas de solución, se queda el tema del turismo, aunque algunos restaurantes cerraron, han estado abriendo con el $30 \%$, pero se sabe que el turismo en general está muy afectado, en el caso de Ixtapaluca las zonas arqueológicas han permanecido cerradas.

Observamos empresas locales que tuvieron que cerrar por la falta de ventas. Como el local de las empresas André Badi e Íntima, Hogar Mx. La apertura de las plazas comerciales, los complejos de cine, restaurantes, gimnasios, han podido ayudar a dar la reactivación económica y la contratación de los trabajadores. Se observa una mayor cantidad de trabajos informales en tianguis, puestos en la calle y negocios en domicilios, para subsanar la falta de ingreso familiar.

Otra cuestión que queda por investigar es más en cuestión de uso del del internet, ya que antes de la Pandemia no se realizaban tantas compras por internet, debido al miedo al uso de internet, por no tener una tarjeta de crédito ó debito de proporcionar datos de las tarjetas de crédito o débito, por el miedo al robo de información, pero ahora con la necesidad de usar el internet, de no salir de casa, el miedo al contagio del Covid-19, el consumidor ha tenido que aceptar y adaptarse a marchas forzadas a usar la tecnología para hacer la mayoría de sus compras y a usar los servicios que se venden y ofrecen por internet. Por supuesto los bancos y las empresas han tenido que fortalecer la seguridad para dar confianza al consumidor y que realice sus compras.

Aunque también ha estado implicado el marketing generacional que básicamente las generaciones $\mathrm{Z}, \mathrm{Y}, \mathrm{X}^{1}$ han estado y les ha sido más sencillo usar las tecnologías y realizar sus compras en internet y actualizarse en el uso de otras herramientas tecnológicas.

Cuáles serán las nuevas redes sociales y las nuevas Apps por usarse, el TikTok, el Content Video, la adopción de realidad aumentada, localización, crear páginas basadas en la ubicación para promover eventos locales u ofertas pequeñas en sucursales, esas son las recomendaciones de expertos en marketing, por lo que las empresas sin importar el tamaño deben tomar en cuenta, como las estarán usando las empresas, sobre todo las locales.

\section{Conclusiones}

Se cumplen los objetivos planteados respecto a conocer las estrategias mercadológicas que las empresas de los Municipios y la Alcaldía seleccionadas, han usado a largo de esta Pandemia del 19 de marzo al 30 de septiembre del 2020, y las Apps que han usado los estudiantes durante esta Pandemia, se dio respuesta a la pregunta de investigación, el uso de redes sociales y las Aplicaciones (Apps) que más se están usando son el Facebook

\footnotetext{
${ }^{1}$ Marketing generacional, ver Kotler (2017).
} 
y el WhatsApp, el uso de la aplicación de Bancomer o BBVA, Banco Azteca, se compra a través de la página de Mercado libre, para la educación el Microsoft Teams, Classroom y Zoom han sido las plataformas más utilizadas, las más descargadas.

El uso del código QR en restaurantes son una ayuda, pensando en el sector turístico, que, aunque no ha podido recuperarse, los restaurantes, fondas y otros lugares de comida han ofrecido esa opción y el comensal se siente seguro al no tener que tocar las cartas.

El uso de catálogos digitales, catálogo web, los envíos a domicilio han ayudado a las empresas porque ha permitido que los intermediarios, asociados de otras empresas, los usen para continuar con sus ventas de cambaceo. Aunque también se les apoyo con varias estrategias de promoción al vendedor, como ofertas, descuentos, envíos a Domicio gratis, para que mantuvieran sus ventas. Las empresas también actualizaron sus productos, adaptándolos a la situación, con la producción de cubrebocas.

El gobierno estatal y municipal por su parte, ha venido realizado toda la campaña para informar al consumidor y al vendedor, en Ixtapaluca, todos los días se informa a la sociedad de cómo amanece el semáforo. Tanto el Estado de México como la Ciudad de México entregaron las indicaciones para el regreso seguro y la apertura escalonada de los diferentes establecimientos y las medidas que se deben tomar, se observa que esto se ha venido aplicando adecuadamente.

\section{References:}

1. Association, A. M. (01 de Diciembre de 2017). marketingdirecto.com. https://www.marketingdirecto.com/punto-de-vista/la-columna/31definiciones-de-mercadotecnia-9

2. CEPAL (2020). Sectores y empresas frente al Covid-19: emergencia y reactivación. Comisión Económica para América Latina y el Caribe (CEPAL).

https://repositorio.cepal.org/bitstream/handle/11362/45734/4/S20004 38_es.pdf

3. CEPAL (2020). Sectores y empresas frente al COVID-19: emergencia y reactivación.

https://www.cepal.org/sites/default/files/presentation/files/finalfinalde_la_crisis_a_la_reactivacion_ppt_-ab4.pdf

4. Chiavenato, I. (2004). Introduccion a la Teoria General de la Administraciòn. McGraw-Hill .

5. Fischer (2020). Estrategias de Mercadotecnia en Mercados específicos. UNAM-FCA.

6. Fischer, L., \& Espejo, C. J. (2017). Mercadotecnia. Mc Graw Hill. 
7. Gobierno de México (2020). Aviso epidemiológico. 27 de febrero del 2020.

https://www.gob.mx/cms/uploads/attachment/file/537574/AvisoEpid emiol_gico_COVID19_27022020_FINAL.pdf

8. Gobierno de México (2020). Comunicado Técnico Diario Nuevo Coronavirus en el Mundo (COVID-19). 28 de febrero del 2020. https://www.gob.mx/cms/uploads/attachment/file/538453/Comunicad o_Tecnico_Diario_COVID-19_2020.02.28.pdf

9. Gobierno de México (2020). Comunicado Técnico Diario Nuevo Coronavirus en el Mundo (COVID-19). 29 de febrero de 2020. https://www.gob.mx/cms/uploads/attachment/file/538454/Comunicad o_Tecnico_Diario_COVID-19_2020.02.29.pdf

10. Gobierno de México (2020). Informe Técnico Diario COVID-19 MÉXICO. 30 de septiembre del 2020. Gobierno de México. https://www.gob.mx/cms/uploads/attachment/file/581593/Comunicad o_Tecnico_Diario_COVID-19_2020.09.30_1_.pdf

11. INEGI (2010). Panorama sociodemográfico de México. http://www.inegi.org.mx/prod_serv/contenidos/espanol/bvinegi/prod uctos/censos/poblacion/2010/panora_socio/mex/Panorama_Mex.pdf

12. INEGI (2010). Síntesis Estadística Municipal, Nezahualcóyotl. (INEGI, Ed.) México.

http://www.inegi.org.mx/est/contenidos/espanol/sistemas/sem10/defa ult.htm

13. INEGI (2012). Clasificación de actividades económicas. file:///C:/Users/Usuario/Downloads/Clasificacion_act_econENOE.pd $\mathrm{f}$

14. INEGI (2014). Censos Economicos 2014. http://www.inegi.org.mx/est/contenidos/proyectos/ce/ce2014/default. aspx

15. INEGI (2015). Directorio estadístico de unidades económicas (DENUE). Aguascalientes, México.

http://www3.inegi.org.mx/sistemas/mapa/denue/default.aspx

16. INEGI (2019). INEGI. Obtenido de cuentame.inegi.org.mx

17. Kotler, P. (2017). Fundamentos de Marketing. Pearson.

18. Marketing, C. (2020). Coktail Marketing. Agencia de Marketing Digital. https://cocktailmarketing.com.mx/

19. Mendoza, H. (2004). Moviles, nuevas vias a la comunicacion. IPMARK.

20. Münch, L. (2010). Administración. Gestión organizacional, enfoques y proceso administrativo. Pearson.

21. Münch, L. (2011). Administración. Pearson Educación.

22. Organizacion Mundial de la Salud (2020). 
https://www.who.int/es/emergencies/diseases/novrl-coronavirus-2019

23. Sauleda, Z. (23 de Enero de 2018). Arpen Technologies. https//arpentechnologies.com/es/blog/aplicaciones-movilcaracteristicas/

24. Snicket, L. (2011). libro blanco de las aplicaciones móviles. Mobile marketing association.

25. Taylor, F. W. (S/A). Administración industrial y General. Ateneo. 